Submitted to the ASCE Journal of Engineering Mechanics, February 2005

Revised, July 2007

\title{
Dynamic Fragmentation of an Ultra-High Strength Concrete during Edge-On Impact Tests
}

\author{
Pascal FORQUIN ${ }^{1,2}$ and François HILD ${ }^{2, *}$
}

\author{
${ }^{1}$ DGA/CTA-Département MSP
}

16 bis avenue Prieur de la Côte d'Or, F-94114 Arcueil Cedex, France now at LPMM, CNRS-UMR7554 / Université Paul Verlaine de Metz Ile du Saulcy, F-57045 Metz Cedex 1, France

${ }^{2}$ LMT-Cachan, ENS de Cachan / CNRS-UMR 8535 / Université Paris 6 61 avenue du Président Wilson, F-94235 Cachan Cedex, France

*to whom correspondence should be addressed.

Fax: +33 1474022 40, Email: hild@lmt.ens-cachan.fr 


\title{
Dynamic Fragmentation of an Ultra-High Strength Concrete during Edge-On Impact Tests
}

\author{
by \\ Pascal FORQUIN and François HILD
}

\begin{abstract}
:
To understand and model damage generated during impact by a penetrator of ultra-high strength concrete targets, edge-on impact tests are performed with the so-called Ductal ${ }^{\mathbb{R}}$ concrete, which is unreinforced or reinforced with short fibers. Two edge-on impact configurations are designed with a dynamic confinement system. The first configuration uses aluminum projectiles and allows us to study the dynamic fragmentation that spreads out within the tile without any confined damage close to the impact point. The fragmentation process is composed of numerous oriented millimetric cracks. In the second configuration, steel projectiles are used with a higher impact velocity. Damaged zones are visualized by using an ultra-high speed camera and a sarcophagus configuration designed to prevent the fragments from moving. The post-mortem studies of impacted tiles enable us to observe an intense fragmentation of the targets and confined damage close to the impact point if steel projectiles are used. Simulations are performed with an anisotropic damage model coupled with a concrete plasticity model. Orientation and crack density are compared with postmortem observations.
\end{abstract}

\section{CE Database Subject Headings:}

Cracking, Damage patterns, Dynamic test, Probabilistic models. 


\section{Introduction}

For several years, defense organizations have been interested in the dynamic behavior of new concrete materials, e.g., Ultra-High Strength Concrete (UHSC). Quasi-static mechanical properties of concrete have increased considerably in less than 20 years (Malier 1992). The use of superplastifiers, silica fumes led since the middle of the 1990s to UHSC concrete materials with a compressive strength of about $-200 \mathrm{MPa}$ to be compared with that of ordinary concrete of about $-30 \mathrm{MPa}$. Research programs that aim at evaluating their ballistic performance are currently under way. One of the goals is to improve the knowledge and modeling of these new materials. In the present study, the so-called Ductal ${ }^{\circledR}$ concrete produced by Lafarge is investigated. Besides its compressive strength (-200 MPa), this UHSC is of interest to be produced on an industrial scale.

Ductal ${ }^{\circledR}$ concrete is one industrial application of investigations on Reactive Powder Concrete (RPC) and belongs to the RPC family for its composition and to the USHC family for its mechanical properties. RPC is characterized by a strict control of the microstructure. A significant increase of flexural strength and ductility is obtained by adding fibers during the process. Behloul (1996) studied the influence of different volume fractions of fibers, namely $0 \%, 1 \%, 2.4 \%, 4 \%$. As far as the compressive strength and fracture energy are concerned, $2.4 \%$ is the optimal percentage. The influence of fiber orientation on the flexural strength of RPC was also underlined (Behloul 1996; Boulay et al. 1997). Other studies were performed by Bayard (2003) who showed the existence of fiber clusters in Ductal ${ }^{\circledR}$ that may induce a heterogeneous behavior of the material. The aim of the present paper is to investigate the damage pattern of this class of materials when impacted by a hard projectile.

When a kinetic penetrator hits a thick target made of a brittle material, a compressive wave propagates in its volume and causes severe degradations. Compressive stresses induce 
isotropic damage under confined conditions close to the impact point (Forquin 2003). Moreover, the radial displacement that follows the compressive wave generates hoop tensile stresses in the target and produces fragmentation (i.e., initiation and propagation of numerous oriented microcracks). This fragmentation was observed in details during edge-on impact experiments on monolithic ceramics (Strassburger and Senf 1994; Strassburger et al. 1994; Riou et al. 1998; Denoual and Hild 2000) and on a porous silicon carbide impregnated or not with an aluminum alloy (Forquin et al. 2003). The use of an ultra-high speed camera allows for the observation of a damage pattern made of micro-cracks oriented in the radial direction that develops from the impact edge to the opposite face. The ceramic tile is mainly damaged before any wave reflection. An anisotropic damage model was proposed to predict the orientation and crack density (Denoual and Hild 2000; 2002).

Few hundred microseconds after impact, the projectile penetrates a highly damaged target. The projectile/target interaction is influenced by the two previous damage regimes. Their understanding and characterization are essential to describe the projectile penetration and the target residual strength. To reproduce these damage mechanisms and to validate damage models, two edge-on impact configurations are designed with a new dynamic confinement system. Aluminum projectiles are used in the first configuration while steel projectiles are utilized for the second series of tests. First, the basic quasi-static mechanical properties of Ductal ${ }^{\circledR}$ are presented in relation with its microstructure. Second, the design of two edge-on-impact configurations is discussed. Third, ultra-high speed camera observations and post-mortem studies are examined. Last, the damage regimes are modeled and numerical simulations are compared with experimental observations. 


\section{Microstructure and basic mechanical properties of Ductal ${ }^{\circledR}$}

Ductal $^{\circledR}$ by its composition and fabrication belongs to the RPC family. In addition to the use of superplastifier and silica fumes, an RPC benefits from a reduced grain size (maximum size $<600 \mu \mathrm{m})$ and an optimal granular skeleton that enables one to homogenize the elastic properties of the grains and the matrix, and to decrease internal stresses (Richard and Cheyrezy 1995). Grain families are strictly separated by size. For example, the dimension of fine sand grains in Ductal ${ }^{\circledR}$ is of the order of a few hundred micrometers (Figure 1), followed by cement grains and crushable quartz grains whose size is about tens of micrometers. A compact arrangement is obtained by using silica fumes. It enables one to reduce the amount of water $[$ water $/($ cement + silica fumes $)=0.13-0.17$ in weight $]$ and to minimize the porosity. The compressive strength is also increased thanks to a small contrast of elastic properties between the matrix and the grains. It follows that the stress concentrations are reduced at the interfaces. In its commercial composition, the Ductal ${ }^{\circledR}$ matrix is reinforced by steel fibers (length: $13 \mathrm{~mm}$, diameter: $0.2 \mathrm{~mm}$, strength: $2400 \mathrm{MPa}$ ). In the present study, the role of the fibers is assessed by looking at ballistic impact experiments. The elastic properties of Ductal ${ }^{\circledR}$ with or without fibers are obtained by using ultrasound experiments. The velocities of longitudinal and transverse waves are measured and the elastic properties of an isotropic and elastic material are deduced (Kolsky 1963). Table 1 summarizes these results. The Young's modulus of Ductal ${ }^{\circledR}$ reinforced by fibers appears slightly greater than that of Ductal ${ }^{\circledR}$ without fibers whereas the Poisson's ratios are identical.

To evaluate the fracture properties under quasi-static loading condition, 3-point flexural experiments are carried out with beam samples. Beams of size $11 \times 10 \times 150 \mathrm{~mm}^{3}$ were cut from a $30 \mathrm{~mm}$ high tile. The tensile surface of the beams corresponds to the center plane of the tile so that a good distribution of fibers (i.e., density and orientation) is expected (Behloul 
1996). The crack initiation stresses for the materials studied herein are scattered. Consequently a Weibull model is used to account for the scatter of the crack initiation stresses as well as volume and stress heterogeneity effects. It can be noted that the Weibull model mainly describes the crack initiation conditions. It has been shown to be relevant for brittle materials such as ceramics (Jayatilaka 1979), glasses (Kurkjian 1985), lightly reinforced concrete (da Silva et al. 2004), and some metals (Beremin 1983) under tensile loading. In that case, the weakest link hypothesis applies. However, for quasi-brittle materials such as ordinary concrete, it has been shown that the corresponding size effects are not necessarily realistic (Bažant 1984; 2000) because a whole process zone develops prior to failure instead of a single cracking event. In the present study, a Weibull model $(1939 ; 1951)$ is used to describe crack initiation. The failure probability $P_{F}$ of a domain $\Omega$ is expressed as

$$
P_{F}=1-\exp \left[-V_{\text {eff }} \lambda_{0}\left(\frac{\left\langle\sigma_{F}\right\rangle}{\sigma_{0}}\right)^{m}\right],
$$

where $V_{\text {eff }}$ denotes the effective volume (Davies 1973)

$$
V_{\text {eff }}=\int_{\Omega}\left[\frac{\left\langle\sigma^{*}(\mathbf{x})\right\rangle}{\sigma_{F}}\right]^{m} d \mathbf{x} \text { with } \sigma_{F}=\max _{\Omega} \sigma^{*}(\mathbf{x})
$$

corresponding to an equivalent stress $\sigma^{*}$ (e.g., maximum principal stress) at a given point $\mathbf{x}$. The parameter $m$ is the Weibull modulus (i.e., it measures the scatter; the lower $m$, the higher the scatter), $\sigma_{0}$ the stress parameter relative to a reference density $\lambda_{0}$, and $\langle$.$\rangle the Macauley$ brackets (i.e., the positive part of '.'). The constant $\sigma_{0}^{m} / \lambda_{0}$ is the Weibull scale parameter. By using a beam theory and neglecting the shear stresses, the effective volume can be calculated in 3-point flexure 


$$
V_{\text {eff }}=\frac{V}{2(m+1)^{2}},
$$

where $V$ is the loaded volume (i.e., $V=11 \times 10 \times 130 \mathrm{~mm}^{3}$ ). For the Weibull model, the average failure stress $\sigma_{w}$ is given by

$$
\sigma_{w}=\sigma_{0}\left(V_{e f f} \lambda_{0}\right)^{-\frac{1}{m}} \Gamma\left(\frac{m+1}{m}\right),
$$

where $\Gamma$ is the Euler function of the second kind (Abramowitz and Stegun 1965). Equation (4) accounts for the scatter of the failure stress as well as volume and stress heterogeneity effects in geomaterials (Hild et al. 2003). Table 1 shows the Weibull moduli $m$ and average stress $\sigma_{w}$ related to crack initiation. In fiber reinforced Ductal ${ }^{\circledR}$, crack initiation may differ from the ultimate strength. Figure 2 shows the maximum tensile stress given by a beam solution as a function of the crosshead displacement obtained for 3-point flexural tests. The failure of unreinforced Ductal ${ }^{\circledR}$ is brittle and caused by porosity within the bulk. Consequently, the crack initiation stress corresponds to the ultimate strength. An example of failure pattern of unreinforced Ductal ${ }^{\circledR}$ is shown in Figure 3a. A large porosity $(\approx 0.6 \mathrm{~mm}$ in diameter) can be seen close to the tensile surface (upper surface of Figure 3a) and is the likely cause of failure. The flexural behavior of reinforced Ductal ${ }^{\circledR}$ is different. As shown by the two stress / displacement curves of Figure 2, 'displacement-hardening' or 'displacementsoftening' is observed. Thus, the load level does not decrease quickly despite crack initiation that corresponds to the loss of linearity in the stress / displacement curve. As shown in Figure $3 b$, the fibers are bridging cracks thereby enhancing the ductility of the material. Even though the mean ultimate strength is larger $(25 \mathrm{MPa})$ than that of unreinforced Ductal ${ }^{\circledR}(22$ $\mathrm{MPa})$, the mean crack initiation stress $(17 \mathrm{MPa})$ is lower. This result is probably the consequence of an excess of large porosities and fiber clusters in reinforced Ductal ${ }^{\circledR}$ in 
comparison with the unreinforced material. The porosity is trapped in the reinforced material during the vibration process. Furthermore, while the crack initiation stress scatter of reinforced Ductal ${ }^{\circledR}$ is quite small (i.e., $m=14$ ) and close to the unreinforced material (i.e., $m=11$, see Table 1), the scatter in terms of ultimate strength is much more important (i.e., $m=3.4$ ). This phenomenon is due to a heterogeneous distribution (density and orientation) of fibers in the material. The existence of fiber clusters decreases the properties of the reinforced concrete (Bayard 2003).

\section{Design of edge-on impact tests}

Tensile multiple-cracking is one of the major degradation mechanisms that occur during impact of a rigid projectile against a thick target made of a brittle material such as concrete, glass or ceramic materials. However, the kinetics and density of cracking are difficult to study since such damage takes place in the bulk of the target. This is why, laboratory impact tests called Edge-On Impact (EOI) were developed by the Ernst-Mach-Institute (EMI) in Germany (Hornemann et al. 1984; Strassburger et al. 1994) and by the Centre Technique d'Arcueil (CTA) in France (Denoual et al. 1998; Riou et al. 1998). During such test, a cylindrical projectile hits the edge of a tile for which the thickness is close to the projectile diameter. In the wake of the compressive wave, tensile hoop stresses develop within the target, a consequence of the radial motion due to the compressive wave. A high-strain-rate tensile loading (in the range of some hundreds to thousands of $\mathrm{s}^{-1}$ ) is obtained far away from the impact point (at a distance of up to ten diameters of the projectile). The damage mechanism is similar to that induced in real impact configurations (Denoual et al. 1996). However, the visualization of damage is easier to perform than for thick targets.

In the present study, new configurations of edge-on impact tests were designed to analyze damage regimes in Ductal ${ }^{\circledR}$ tiles. These configurations are composed of a concrete tile, the 
cylindrical projectile (made of aluminum alloy or steel), an aluminum sarcophagus (not used with the high speed camera) and a confinement system made of two tungsten half-cylinders, two steel half-rings (Figure 4). The latter is used to avoid or to reduce as much as possible a first damage due to compressive stresses close to the impact point. It is based on the fact that the compressive strength of the studied concrete is known to be sensitive to the hydrostatic stress (Buzaud 1998). The higher the pressure, the higher the strength of concrete. It works in the following way. The half-rings and half-cylinders are put in contact with the lateral faces of the concrete tile near the impact point. The material used for the cylinders (i.e., tungsten) was selected for its large impedance. The loading in front of the projectile is virtually a plane strain compressive field. The lateral compressive stresses applied by this confinement are the result of the axial compression of the projectile and inertia effects of the confinements. The higher the axial load, the higher the hydrostatic pressure in the area close to the impact point, the higher the strength and the lower the damage of the material due to compressive stresses. Therefore, no additional static loading is needed to ensure a good confinement. That is the reason why the system is referred to as "dynamic confinement."

Based upon this concept, two configurations are developed. The first one is designed to avoid confined damage whereas the second one favors confined damage in the vicinity of the confinement system. These two configurations are discussed below. Dimensions of projectiles, tiles and confinements are selected in relation with the gas launcher capabilities. The projectile diameter (i.e., $20 \mathrm{~mm}$ ) is imposed by the gas gun, whereas its length (i.e., $50 \mathrm{~mm}$ ) allows for compression without wave reflection during $20 \mu \mathrm{s}$. The tile thickness is chosen small (i.e., $10 \mathrm{~mm})$ whereas the tile length and width $\left(300 \times 150 \mathrm{~mm}^{2}\right)$ are sufficient to develop a damage pattern with small disturbance due to wave reflections. The external diameter of the half-cylindrical confinement $(24 \mathrm{~mm})$ enables one to preserve the $2 \mathrm{D}$ aspect of the loading within a wide zone of observation. Tungsten cylinders were only available 
with a $13-\mathrm{mm}$ diameter. Consequently, half-rings made of steel are placed side by side the tungsten half-cylinders (Figure 4).

The two configurations are analyzed by performing numerical simulations with the explicit FE code Pamshock (2001). At this stage of design, a simple constitutive equation is used. This modeling aims at evaluating tensile stresses within the tile and compressive stresses beyond the confined area, thus a model able to describe the ultimate strength in the confined zone is needed. Triaxial compression tests were performed on Ductal ${ }^{\circledR}$ concrete (Buzaud 2003; Forquin 2003). The 'deviatoric' strength observed under high pressure $(|\mathrm{P}| \geq 200 \mathrm{MPa})$ was almost constant and axial strains can reach up to $10 \%$. Consequently, an elastoplastic model following a $J_{2}$ flow rule is chosen for the target with a yield stress $\sigma_{\mathrm{y}}$ equal to $400 \mathrm{MPa}$. This value corresponds to the strength of an UHSC in quasi-oedometric compression (Buzaud 2003; Forquin 2003). The mesh used is shown in Figure 5a. This computation shows that when an aluminum projectile is used the von Mises equivalent stress remains less than the yield stress in the confined zone (Figure 5b) and the minimum principal stress level remains less than the compressive strength (i.e., $-220 \mathrm{MPa}$ ) beyond the confined area. Consequently, it is expected that confined damage should not occur in this first configuration.

In the second case utilizing a steel projectile, the von Mises equivalent stress reaches $400 \mathrm{MPa}$ up to $20 \mathrm{~mm}$ in front of the impact point and the minimum principal stress exceeds the $-220-\mathrm{MPa}$ limit for a distance greater than $40 \mathrm{~mm}$ from the impact point (Figure $5 \mathrm{c}$ ). Two damaged zones are expected to occur. Damage due to confined compression in the first area below the dynamic confinement (i.e., up to $20 \mathrm{~mm}$ from the impact point), a damage representative of a weakly confined compression in the second area $(20-40 \mathrm{~mm}$ from the impact point) that may be coupled with a dynamic fragmentation process. Even when the first configuration is used, the pressure reaches the 350-MPa level in the confined zone $8 \mu$ s after 
impact and confirms the usefulness of the dynamic confinement (Figure 5d). As was observed during the above-mentioned triaxial compression tests, the strength of Ductal ${ }^{\circledR}$ increases with the pressure to reach less than $-400 \mathrm{MPa}$ for a $300-\mathrm{MPa}$ pressure (Buzaud 2003; Forquin 2003).

\section{Use of an ultra-high speed camera}

An ultra-high speed camera was used to visualize the development of the fragmentation process. Figure 6 shows a schematic of the experimental set-up. A sarcophagus is put in an aluminum container. The projectile speed is measured by two optical cells $50 \mathrm{~mm}$ apart. When the projectile reaches the second cell, flashes are triggered and when it impacts the edge of the target, the camera is activated to take pictures. To increase contrast, the ultra-high speed camera is aligned along the reflection axis of the flashlights and the concrete tiles are slightly polished. The region of interest is reduced $(60 \mathrm{~mm})$ to facilitate the observation of damage.

Only steel projectiles were used with an impact velocity close to $130 \mathrm{~m} / \mathrm{s}$. Damage appears $12 \mu \mathrm{s}$ after impact (Figures 7a, 7b) and curved cracks develop until $20 \mu \mathrm{s}$ after impact. Then, the damage zone darkens and probably moves from the observed plane. This compressive damage develops within a zone localized at a distance less than $40 \mathrm{~mm}$ from the impact point. Furthermore, $44 \mu$ s after impact, straight radial cracks appear corresponding to the dynamic fragmentation process. This second damage process spreads out all over the observed window. Spall cracks, oriented perpendicularly to the projectile axis, are observed $44 \mu \mathrm{s}$ after impact $70 \mathrm{~mm}$ from the impact point. The distance between spall cracks and the rear edge $(60 \mathrm{~mm})$ corresponds approximately to the projectile length $(50 \mathrm{~mm})$. The time to initiation is consistent with a wave velocity close to $5000 \mathrm{~m} / \mathrm{s}$ (38 $\mu \mathrm{s}$ are required to travel $190 \mathrm{~mm}$ ). A lower crack density seems to occur for a reinforced material (6 radial cracks and 
1 spall crack are seen in Figure $7 b$, as opposed to 11 radial cracks and 6 spall cracks, Figure 7a). As the post-mortem study will show, fibers may reduce the crack openings without actually modifying the crack density.

\section{Post-mortem studies of edge-on impact tests}

A so-called sarcophagus configuration is used (Denoual et al. 1998) to maintain the fragments in place and to observe the macroscopic and microscopic post-mortem cracking pattern (Figure 4). The impedance of the aluminum confinement needs to be less than that of the concrete tile so that the "confinement" does not interfere with the impacted tile. After impact, the sample is infiltrated by a hyper-fluid resin and polished for macroscopic and microscopic analyses (Figure 8).

The first post-mortem study corresponds to an edge-on impact by an aluminum projectile with a velocity of $88 \mathrm{~m} / \mathrm{s}$ (Figure $8 \mathrm{a}$ ). Different zones can be separated with respect to the cracking pattern and density. Two zones appear intact corresponding to the contact surface of the tungsten half-cylinder and the steel half-ring. As predicted by the numerical simulation, the dynamic confinement prevents damage to develop close to the impact point. Beyond this undamaged zone, a damaged area spreads out between a radius of 12 and $20 \mathrm{~mm}$. The absence of dynamic confinement in that area probably favors the development of damage. This observation confirms the usefulness of the dynamic confinement system. An intense fragmentation is also visible beyond the previous zones composed of cracks oriented in the radial direction. This damage zone spreads over more than $80 \mathrm{~mm}$. A crack density in the range of $10^{7}-2.10^{7}$ cracks per $\mathrm{m}^{3}$ was estimated between radii of 30 and $50 \mathrm{~mm}$. It is based upon the evaluation of the mean distance between consecutive cracks along partial circular paths emanating from the impact point. The measurement uncertainty is evaluated of the order of a few cracks for about ten cracks detected along the considered partial circular 
paths. Two spall cracks oriented perpendicular to the axial direction are also visible at a distance of $60 \mathrm{~mm}$ from the impact point.

The damage pattern of the second configuration (Figure $8 \mathrm{~b}$ ) is very different. Three damage modes are observed as a function of the distance from the impact point. The confined zone is totally damaged and reduced in debris in spite of fibers that reinforce the target. Close to this comminuted area, cracks always oriented at $45^{\circ}$ with respect to the radial and hoop directions are seen. These cracks, called snail cracks, develop in mode II with rubbing faces. Far away from the confinement, one also observes numerous circular-front cracks centered on the impact point. These cracks are thought to emerge to the surface leading to the dark areas observed on pictures given by the ultra-high speed camera between $16 \mu$ s and $44 \mu$ s after impact. These "emerging crack" or "shell cracks" might be the result of unconfined compression beyond the confined area, similar to the splitting mode observed in uniaxial compression of concrete samples. These cracking mechanisms correspond to more or less confined compressive damage due to radial compression stresses. The dimension of the area affected by this compressive damage $(40 \mathrm{~mm})$ is in good agreement with that predicted by numerical simulation using a von Mises criterion and no hardening law. This confined damage does not prevent an intense fragmentation of the tile at a distance of $40 \mathrm{~mm}$ to $130 \mathrm{~mm}$ from the impact point. This fragmentation is composed of numerous radial cracks, which are few centimeters long. One may also note the presence of spall cracks (not visible in Figure $8 \mathrm{~b}$ ) at a distance of $50 \mathrm{~mm}$ from the rear edge that corresponds to the projectile length.

\section{Numerical analysis of damage induced by impact in concrete}

The fragmentation process is discrete by essence. Several Continuum Damage Mechanics models may be used with an isotropic (Grady and Kipp 1980; Margolin 1983; Rajendran 
1994) or anisotropic (Espinosa et al. 1998; Denoual and Hild 2000) description to account for multiple fragmentation. In the numerical simulations performed herein, the medium is assumed to be continuous on the scale of a finite element in which numerous cracks are expected to form. It may be noted that alternative (discrete) approaches may be followed (Camacho and Ortiz 1996; Mastilovic and Krajcinovic 1999; Ibrahimbegovic and Delaplace 2003). To account for confined damage, the KST model (Krieg 1978; Swenson and Taylor 1983 ) is coupled with a damage model based upon a fragmentation analysis (Denoual and Hild 2000; 2002; Forquin et al. 2003).

\section{KST Model}

The KST model gives a good description of geomaterials behavior under low or high confinement (Schwer et al. 1988). A compaction law is used for the spherical behavior whereas the equivalent stress depends upon the von Mises stress as well as the hydrostatic pressure (Drucker and Prager 1956). The higher the pressure, the higher the strength. This model accounts for the difference of strength in simple and confined compression of geomaterials.

An irreversible volumetric strain is used to describe the unloading part and is defined by

$$
\varepsilon^{i r}=\varepsilon_{v}+\frac{P}{K}
$$

where $K$ is the bulk modulus that depends upon the volumetric strain $\left[K=K\left(\varepsilon_{\mathrm{v}}\right)\right]$. A hydrostatic compression test provides the initial and final bulk moduli $\left(K_{i}, K_{f}\right)$. Between these two extreme values, a linear variation is assumed 


$$
K= \begin{cases}K_{i} & \text { when } \varepsilon_{v} \geq \varepsilon_{v}^{(2)} \\ K_{i} \frac{\varepsilon_{V}-\varepsilon_{V}^{(n)}}{\varepsilon_{V}^{(2)}-\varepsilon_{v}^{(n)}}+K_{f} \frac{\varepsilon_{V}-\varepsilon_{V}^{(2)}}{\varepsilon_{v}^{(n)}-\varepsilon_{V}^{(2)}} & \text { when } \varepsilon_{v}^{(2)} \geq \varepsilon_{v} \geq \varepsilon_{v}^{(n)} \\ K_{f} & \text { when } \varepsilon_{V} \leq \varepsilon_{v}^{(n)}\end{cases}
$$

where $n$ denotes the last point used to define the overall behavior ( $n=4$ in Figure 9). The same test, performed by Buzaud (2003), also provides other points of the compaction curve (i.e., the loading part $\varepsilon_{V}^{(i)}$ vs. $P^{(i)}$ ) that is described by a linear relationship

$$
P= \begin{cases}-K_{i} \varepsilon_{v} & \text { when } \varepsilon_{v} \geq \varepsilon_{v}^{(2)} \\ P^{(i-1)} \frac{\varepsilon_{V}-\varepsilon_{v}^{(i)}}{\varepsilon_{v}^{(i-1)}-\varepsilon_{v}^{(i)}}+P^{(i)} \frac{\varepsilon_{V}-\varepsilon_{v}^{(i-1)}}{\varepsilon_{v}^{(i)}-\varepsilon_{v}^{(i-1)}} & \text { when } \varepsilon_{v}^{(i-1)} \geq \varepsilon_{v} \geq \varepsilon_{v}^{(i)} \\ -K_{f} \varepsilon_{v} & \text { when } \varepsilon_{v} \leq \varepsilon_{v}^{(n)}\end{cases}
$$

When the pressure is known, its effect on the deviatoric response can be accounted for. The equivalent (von Mises) stress is related to the pressure $P$ by a pressure-dependent yield stress $\sigma_{y}(P)$

$$
\sigma_{e q}=\sigma_{y}(P)=\left\{\begin{array}{lll}
\max \left(\sigma_{e q}^{\min }, \sqrt{a_{0}+a_{1} P+a_{2} P^{2}}\right) & \text { when } & \sqrt{a_{0}+a_{1} P+a_{2} P^{2}}<\sigma_{e q}^{\max } \\
\min \left(\sigma_{e q}^{\max }, \sqrt{a_{0}+a_{1} P+a_{2} P^{2}}\right) & \text { when } \sqrt{a_{0}+a_{1} P+a_{2} P^{2}}>\sigma_{e q}^{\min }
\end{array}\right.
$$

In the present study, the stress $\sigma_{e q}^{\min }$ is assumed to be equal to the ultimate strength in a uniaxial compression test. The mean compression strength measured with hourglass samples is equal to $-222 \mathrm{MPa}$ (Forquin 2003). Other triaxial compression tests were performed on Ductal $^{\circledR}$ concrete (Buzaud 2003) to tune the coefficients $a_{0}, a_{1}, a_{2}$ and the maximum equivalent stress $\sigma_{e q}^{\max }$. During these tests, an axial compression is applied on a cylindrical specimen already loaded by a pure hydrostatic stress. The maximum strength is determined 
for different hydrostatic stresses (i.e., $-200,-300,-400$, and $-600 \mathrm{MPa}$ ). The strength versus pressure envelope provides data of the 'deviatoric' limit $\sigma_{e q}\left(a_{0}, a_{1}, a_{2}, \sigma_{e q}^{\max }\right)$. The parameters are given in Table 2. The plastic strain tensor $\mathbf{e}^{p}$ is defined as

$$
\mathbf{e}^{p}=\mathbf{e}-\frac{\mathbf{s}}{2 G}
$$

where $\mathbf{e}$ is the deviatoric part of the total strain tensor, $\mathbf{s}$ the deviatoric stress tensor, and $G$ the shear modulus. The plastic strain increment $d \mathbf{e}^{p}$ is given by

$$
d \mathbf{e}^{p}=d \lambda \frac{\partial \phi_{s}}{\partial \mathbf{s}}=d \lambda \frac{3 \mathbf{s}}{2 \sigma_{e q}}
$$

where $d \lambda$ is the plastic multiplier obtained from the Kuhn-Tucker conditions associated with $\phi_{s}=\sigma_{e q}-\sigma_{y}(P)$.

\section{Fragmentation model}

In the following, a damage model is presented. It is based upon a fragmentation analysis (Denoual and Hild 2000). For brittle materials, the analysis of failure depends upon the microstructure in terms of flaw density and failure stress distribution (Shockey et al. 1974). In the present analysis, it is assumed that cracking occurs normal to three principal directions $\boldsymbol{d}_{\mathbf{i}}(\mathrm{i}=1,2,3)$. The microstructure is approximated by point defects of density $\lambda_{\mathrm{t}}$ with random locations. It is described by a Poisson point process of intensity $\lambda_{t}$ (Gulino and Phoenix 1991; Jeulin 1991; Denoual et al. 1997)

$$
\lambda_{t}\left(\sigma_{i}\right)=\lambda_{o}\left(\frac{\left\langle\sigma_{i}\right\rangle}{\sigma_{o}}\right)^{m}
$$


Equation (11) shows that the higher the local principal stress $\sigma_{i}$, the more defects can break. The intensity of the Poisson process is directly related to the Weibull parameters (Denoual and Hild 2002) that may be identified under quasi-static loading conditions as shown previously. Under impact, multiple fragmentation is observed (Figures 7 and 8) in many brittle materials. The weakest link hypothesis no longer applies on a global scale and the behavior is referred to quasi-brittle. Continuum Damage Mechanics will be used to describe crack networks. In the following, it is assumed that the defect population leading to damage and failure is identical when the material is subjected to quasi-static and dynamic loading conditions (Shockey et al. 1974; Denoual and Hild 2000). To understand why a crack nucleates, one has to model the interaction of a nucleated crack and other defects that would nucleate. The microcrack propagation velocity is assumed to be constant and equal to a fraction $k$ of the longitudinal wave speed $C_{0}$ (Bluhm 1969; Freund 1972; Riou et al. 1998). Therefore, one may define a relaxation or obscuration domain of volume $V_{o}$ around a crack (i.e., a zone in which the stresses are smaller than the applied stresses, thus do not cause new crack initiations)

$$
V_{o}(t-\tau)=S\left[k C_{0}(t-\tau)\right]^{3},
$$

which is a function of a shape parameter $\mathrm{S}$, the present time $t$ and the time to nucleation $\tau<t$. The shape parameter $S$ may depend on the Poisson's ratio $v$ but it is independent of time so that the relaxed zones are self-similar. New cracks will initiate only if the defect exists in the considered zone and if the flaw does not belong to any relaxed zone. It can be noted that the relaxation volumes are associated with a cracking normal $\boldsymbol{d}_{\mathbf{i}}$. The total flaw density $\lambda_{t}$ is split into two parts, namely, $\lambda_{b}$, the crack density and the obscured flaw density. The increment of crack density $\lambda_{b}$ is related to that of total flaw density $\lambda_{t}$ by 


$$
\frac{d \lambda_{b}}{d t}[\sigma(T)]=\frac{d \lambda_{t}}{d t}[\sigma(T)]\left(1-P_{o}(T)\right)
$$

with $\lambda_{b}(0)=\lambda_{t}(0)=0$ and $P_{\mathrm{o}}$ the probability of obscuration associated to the cracking normal $\boldsymbol{d}_{\mathbf{i}}$ (Denoual et al. 1997)

$$
P_{o}=1-\exp \left(-\int_{0}^{t} V_{o}(t-\tau) \frac{d \lambda t}{d t}\left\{\sigma_{i}(\tau)\right\} d \tau\right)
$$

It can be noted that Equation (14) accounts for overlappings of obscuration zones.

When dynamic loadings are considered with a constant stress rate $\dot{\sigma}$, a dimensionless density $\left(\tilde{\lambda}=\lambda / \lambda_{c}\right)$, time $\left(\widetilde{T}=T / t_{c}\right)$, volume $\left(\widetilde{V}=V / V_{c}\right)$ and stress $\left(\tilde{\sigma}=\sigma / \sigma_{c}\right)$ are defined from the condition (Denoual and Hild 1998)

$$
\lambda_{c}=\lambda_{t}\left(t_{c}\right), V_{c}=V_{o}\left(t_{c}\right), \sigma_{c}=\dot{\sigma}_{c}, \text { when } \lambda_{c} V_{c}=1
$$

where the subscript $c$ denotes characteristic quantities. The characteristic time, stress and density are expressed as

$$
\begin{aligned}
& \boldsymbol{t}_{c}=\left(\lambda_{o}^{-\frac{1}{m}} \sigma_{0}\right)^{\frac{m}{m+3}}(\dot{\sigma})^{\frac{-m}{m+3}}\left(S^{\frac{1}{3}} k C\right)^{\frac{-3}{m+3}} \\
& \sigma_{c}=\left(\lambda_{o}^{-\frac{1}{m}} \sigma_{0}\right)^{\frac{m}{m+3}}(\dot{\sigma})^{\frac{3}{m+3}}\left(S^{\frac{1}{3}} k C\right)^{\frac{-3}{m+3}} \\
& \lambda_{c}=\left(\lambda_{o}^{-\frac{1}{m}} \sigma_{0}\right)^{\frac{-3 m}{m+3}}(\dot{\sigma})^{\frac{3 m}{m+3}}\left(S^{\frac{1}{3}} k C\right)^{\frac{-3 m}{m+3}}
\end{aligned}
$$


According to Equation (16), characteristic quantities are related to 3 types of parameters. The first term corresponds to the second Weibull parameter (activation of critical defects), the second term is the stress rate (i.e., related to the load history) and the third one is made of parameters related to the obscuration volume [Equation (12)]. One may note that the powers indicate the sensitivity of the characteristic quantities to the three types of parameters that control the fragmentation process, namely, crack initiation, loading rate and crack propagation. For example, assuming $m \gg 3$, the characteristic time is inversely proportional to the stress rate whereas the characteristic density is proportional to the stress rate raised to the power 3 .

A closed-form solution of the obscuration probability reads

$$
P_{O}=1-\exp \left(-\frac{\Gamma(4) \Gamma(m+1)}{\Gamma(m+4)} \widetilde{T}^{m+3}\right)
$$

By using Equations (11) and (17), the dimensionless crack density becomes

$$
\tilde{\lambda}_{b}(\tilde{T})=\frac{m}{m+3}\left[\frac{\Gamma(m+4)}{\Gamma(m+1) \Gamma(4)}\right]^{\frac{m}{m+3}} \gamma\left(\frac{m}{m+3}, \frac{\Gamma(m+1) \Gamma(4)}{\Gamma(m+4)} \tilde{T}^{m+3}\right)
$$

where $\gamma$ is the incomplete gamma function

$$
\gamma(\alpha, T)=\int_{0}^{T} \exp (-t) t^{\alpha-1} d t
$$

By noting that $\gamma(\alpha, T \rightarrow+\infty) \rightarrow \Gamma(\alpha)$, the normalized crack density at saturation is a function of only the Weibull modulus $m$

$$
\tilde{\lambda}_{b}(\tilde{T}=\infty)=\left[\frac{\Gamma(m+4)}{\Gamma(m+1) \Gamma(4)}\right]^{\frac{m}{m+3}} \Gamma\left(\frac{m}{m+3}+1\right)
$$


The ultimate macroscopic stress $\Sigma_{u}$ may be also computed as the maximum macroscopic stress $\Sigma=\left(1-P_{O}\right) \dot{\sigma}$ with respect to time $t$. The ultimate macroscopic stress (i.e., the dynamic strength) is then the product of the characteristic stress with a function of the Weibull modulus $m$ only

$$
\Sigma_{u}=\sigma_{c}\left(\frac{\Gamma(m+3)}{e \Gamma(4) \Gamma(m+1)}\right)^{\frac{1}{m+3}}
$$

According to Equations (18) and (21), the crack density and the ultimate macroscopic stress are related to the Weibull parameters, the stress rate and the cracking velocity. The Weibull parameters are those of unreinforced Ductal ${ }^{\circledR}$. This choice is consistent with the fact that the initiation parameters are describing microcracking and the latter are almost identical whether $\operatorname{Ductal}^{\circledR}$ is reinforced or not. The Weibull parameters being known, the last parameter of the model are those related to the extension of obscuration volumes [Equation (12)]. The shape parameter $S$ is assumed to be known [in 3D situations $S \approx 3.74$ (Denoual and Hild 2002)]. Cracks being propagating, the cracking velocity ( $\left.V_{\text {cracking}}\right)$ is proportional to the $1 \mathrm{D}$ wave speed (e.g., $V_{\text {cracking }}=k C_{0}$, with $C_{0}=\sqrt{E / \rho}$ ). The value of $k$ is not well known, especially for new grades of concrete materials. Based upon the concept of conservation of energy, an analytical solution for $k$ was proposed (Broek 1982; Kanninen and Popelar 1985). It shows that when the crack length becomes significantly larger than the initial crack size, the cracking velocity tends to a limit close to $0.38 C_{0}$. However, according to Freund $(1972 ; 1990)$, cracks in brittle materials may accelerate up to the Rayleigh wave speed $C_{R}$, e.g., $C_{R}=0.586 C_{0}$ with $v=0.2$. Further, the parameter $k$ was investigated in several brittle materials, in particular when transparent. For example, experimental studies showed a limiting velocity about $0.5 C_{R}$ in glass, about $0.6 C_{R}$ in Plexiglas and about $0.4 C_{R}$ in Homalite-100 (Ravi-Chandar and Knauss 1982; 1984a; 1984b; 1984c; 1984d; Knauss and Ravi-Chandar 1985; 1986; Sharon et 
al. 1995). Strassburger and Senf (1995) also investigated the terminal crack velocity in a silicon carbide and in glass materials and observed a crack velocity approximately half of $C_{R}$ in both cases.

Molecular dynamics simulations were also performed to investigate the crack propagation velocity (Sieradzki and Dienes 1988; Abraham and Gao 2000) and crack branching (Zhou et al. 1996). According to Abraham and Gao (2000), the propagation velocity is bounded by the Rayleigh wave speed in mode I whereas it could reach the longitudinal wave speed in mode II. The above-mentioned studies show a scatter in crack velocity in brittle materials within the range of $0.4 C_{R}$ to $C_{R}$ (or $0.23 C_{0}$ to $0.59 C_{0}$ with $v=0.2$ ) and more in the range of $0.4 C_{R}$ to $0.6 C_{R}$ according to experimental studies (or $0.23 C_{0}$ to $0.35 C_{0}$ with $v=0.2$ ).

To analyze the sensitivity of the model predictions to this parameter, the closed form solutions of the model are used [Equations (15) to (21)]. In particular, the characteristic parameters [Equation (16)] give the explicit dependence of the considered quantity to $k$. The ultimate macroscopic stress and the crack density at saturation are plotted in Figure 10 as functions of $k$, with $k$ ranging between 0.2 and 0.55 , for a stress rate of $10 \mathrm{MPa} / \mu$ s (i.e. $\left.\dot{\varepsilon}=\dot{\sigma} / E \approx 175 \mathrm{~s}^{-1}\right)$. The latter is representative of the edge-on impact experiments reported above, namely a hoop stress rate of the order of $24 \mathrm{MPa} / \mu \mathrm{s}, 14 \mathrm{MPa} / \mu \mathrm{s}, 9 \mathrm{MPa} / \mu \mathrm{s}$ and $5 \mathrm{MPa} / \mu \mathrm{s}$, at a distance from impact point of $20,30,40$ and $50 \mathrm{~mm}$, respectively. The ultimate macroscopic stress scales as $k^{-3 /(m+3)}$ and varies from $22 \mathrm{MPa}$ to $27.5 \mathrm{MPa}$ in the considered range of $k$ [0.2-0.55] (Figure 10). Conversely, the crack density at saturation scales as $k^{-3 m /(m+3)}$, namely, the largest value of the crack density $\left(2\right.$ cracks $\left./ \mathrm{mm}^{3}\right)$ is reached for $k=0.2$, whereas the lowest value $\left(0.2 \mathrm{crack} / \mathrm{mm}^{3}\right)$ is obtained for $k=0.55$. By considering a value $k=0.38$, a crack density of about $0.4 \mathrm{crack} / \mathrm{mm}^{3}$ is obtained. Therefore the crack density predicted by numerical simulations may be compared roughly with that 
deduced from post-mortem observations. The uncertainty on the crack density associated with the value of $k$ is of the same order of magnitude as the measurement uncertainty.

Based upon the fragmentation analysis, a damage model is now developed. The variable $P_{\mathrm{o}}$ is used to define a damage variable in the framework of Continuum Damage Mechanics. The probability $P_{\mathrm{o}}$ is assumed to be equal to the damage variable $D_{\mathrm{i}}$ associated to the direction $\boldsymbol{d}_{\mathbf{i}}$. In the present analysis, an anisotropic description is used so that three damage variables are used associated to each cracking directions assumed to be orthogonal. The strain tensor $\varepsilon$ is related to the macroscopic stress tensor $\Sigma$ by

$$
\boldsymbol{\varepsilon}=\mathbf{K}\left(D_{1}, D_{2}, D_{3}\right) \mathbf{\Sigma}
$$

where the compliance tensor $\mathbf{K}$ is defined as

$$
\mathbf{K}=\frac{1}{E}\left[\begin{array}{cccccc}
\frac{1}{1-D_{1}} & -v & -v & 0 & 0 & 0 \\
-v & \frac{1}{1-D_{2}} & -v & 0 & 0 & 0 \\
-v & -v & \frac{1}{1-D_{3}} & 0 & 0 & 0 \\
0 & 0 & 0 & \frac{1+v}{\left(1-D_{2}\right)^{\alpha}\left(1-D_{3}\right)^{\alpha}} & 0 & 0 \\
0 & 0 & 0 & 0 & \frac{1+v}{\left(1-D_{3}\right)^{\alpha}\left(1-D_{1}\right)^{\alpha}} & 0 \\
0 & 0 & 0 & 0 & 0 & \frac{1+v}{\left(1-D_{1}\right)^{\alpha}\left(1-D_{2}\right)^{\alpha}}
\end{array}\right]
$$

where $E$ is the Young's modulus, $v$ the Poisson's ratio of the undamaged material, and $\alpha=0.5$. The growth of each damage variable $D_{\mathrm{i}}$ is based upon the defect density $\lambda_{t}$ and derived by using Equation (14)

$$
\frac{d^{2}}{d t^{2}}\left(\frac{1}{1-D_{i}} \frac{d D_{i}}{d t}\right)=6 S\left(k C_{0}\right)^{3} \lambda_{t}\left[\sigma_{i}(t)\right] \text { when } \frac{d \sigma_{i}}{d t}>0 \text { and } \sigma_{i}>0
$$

where no index summation is used, and $\sigma_{i}$ denotes the microscopic principal stress. 
In the numerical simulations presented bellow, the constant $k$ is chosen equal to 0.38 as for ceramics (Riou et al. 1998; Denoual and Hild 2000). The model has no other parameters to tune, so the following numerical simulations are predictions.

\section{Model coupling}

For each step, the strain increment is given so that the updated volumetric and deviatoric strain components are known. The pressure is deduced by considering the spherical law of the KST model [Equations (5) or (7)]. The deviatoric strain increment given as input, it is used to compute the deviatoric stress by using Equations (8-10) and to update the plastic strain tensor. The microscopic stress tensor $\sigma$ being computed, it is used to deduce the damage increments [Equation (24)] as well as the crack density increments [Equation (13)] when any component of the principal stress is positive. The macroscopic stress tensor is then deduced

$$
\boldsymbol{\Sigma}=\mathbf{K}^{-1}\left(D_{1}, D_{2}, D_{3}\right) \mathbf{K}(0,0,0) \boldsymbol{\sigma}
$$

At the end of each step, the user has access to the damage variables along three cracking directions, the macroscopic stresses as well as the crack density. Depending on the problem, any of these quantities may be visualized.

\section{Finite Element computations}

Finite element simulations are performed with the commercial explicit code Abaqus (Hibbitt et al. 2001) in which the coupled model is implemented via a VUMAT routine. In the present case, we will focus on the crack density along the maximum principal stress direction and the corresponding damage variable.

Numerical simulations of the two previous configurations (impacts with aluminum and steel projectile with velocities of 88 and $130 \mathrm{~m} / \mathrm{s}$ ) are performed with the coupled model. 
Damage spreads out within half the concrete tiles $30 \mu$ s after impact (Figures 11a, 12a). The targets are fully damaged $45 \mu$ s after impact (Figures $11 \mathrm{~b}, 12 \mathrm{~b}$ ). This result is consistent with the pictures from ultra-high speed camera (Figure 7). In particular, the $5^{\text {th }}$ picture obtained 44 $\mu \mathrm{s}$ after impact allows one to note the main radial cracks that are clearly visible on the last picture $(100 \mu$ s after impact).

Comparing Figures 11 and 12, the patterns of damage and crack density predicted by the two numerical simulations are very similar despite the difference of projectiles and velocities. This is also consistent with the similar fragmentation patterns at a distance of $40 \mathrm{~mm}$ to $130 \mathrm{~mm}$ from the impact point observed on the two post-mortem studies (Figures $8 \mathrm{a}$ and $8 \mathrm{~b}$ ). The crack densities have to be compared quantitatively. In both cases (Figures 11 and 12), the crack density is about $10^{9}-10^{8.5}$ cracks $/ \mathrm{m}^{3}$ at a distance of 30 to 50 $\mathrm{mm}$ from the impact point. Therefore the predicted crack density is slightly greater than that observed during edge-on impact tests (in the range of $10^{7}-2 \times 10^{7}$ cracks per $\mathrm{m}^{3}$ in the same area, Figure 8). Beyond half of the concrete tiles, the predicted crack density decreases below $10^{8}$ cracks $/ \mathrm{m}^{3}$, which may explain the long radial cracks visible on the post-mortem studies. Moreover, EOI tests were performed on tiles made of Ductal ${ }^{\circledR}$ without fibers (Forquin 2003). The patterns of crack density were unchanged in comparison with that of Figures $8 \mathrm{a}$ and $8 \mathrm{~b}$. Therefore, one may think that fibers do not avoid or reduce cracking and crack propagation even though the residual strength increases significantly when fibers are used. This result confirms that Weibull parameters associated with crack initiation can be used to model dynamic fragmentation. The present model allows us to reproduce reasonably the characteristic time to damage, the orientation of cracking as well as the pattern of crack density (even if the crack density is slightly oversestimated). Therefore, the coupled KSTfragmentation model is able to predict the damage process of Ductal ${ }^{\circledR}$ resulting from an impact loading whether the concrete matrix is reinforced or not by short fibers. 


\section{Summary}

Edge-on impact tests were designed and performed by studying an ultra-high strength concrete Ductal ${ }^{\circledR}$ reinforced or not by small fibers. A dynamic confinement was used to reduce or avoid confined damage close to the impact point. Numerical simulations performed with a simple elastoplastic model predict a fragmentation without compressive damage for the first configuration (aluminum projectile, impact velocity $=88 \mathrm{~m} / \mathrm{s}$ ) whereas two damaged zones are expected to occur with the second configuration (steel projectile, impact velocity $=130 \mathrm{~m} / \mathrm{s}$ ). These two zones are indeed observed by using an ultra-high speed camera. Confined damage develops between $12 \mu$ s and $44 \mu$ s after impact and fragmentation is activated subsequently.

An intense fragmentation process made of numerous radial cracks is seen in postmortem analyses when an aluminum projectile is used, whereas two different damage patterns are obtained with the second configuration using a steel projectile. The first one, which is localized close to the impact point, is generated by the compressive state of stress. This damage does not prevent fragmentation within the target. These results confirm the usefulness of the dynamic confinement system. Fibers do not appear to be an obstacle to the initiation of damage even though they may provide a higher residual strength.

The coupled model describing fragmentation, compaction and confined damage enables us to get a good prediction of damage (pattern, crack density and orientation) even if the crack density is over-estimated. This can be explained by the low level of crack openings that are not easy to visualize. 


\section{Acknowledgements}

This work was funded by the Délégation Générale pour l'Armement (DGA). The authors acknowledge useful discussions with Dr. L. Rota.

\section{References}

Abraham, F., and Gao, H. (2000). "How Fast Can Cracks Propagate?" Phys. Rev. Lett., 84 (14), 3113-3116.

Abramowitz, M., and Stegun, I. A. (1965). Handbook of Mathematical Functions. Dover Publications, Inc., New York (USA).

Bayard, O. (2003). "Approche multi-échelles du comportement mécanique des bétons à ultra hautes performances renforcés par des fibres courtes." $\mathrm{PhD}$ dissertation (in French), Ecole Normale Supérieure de Cachan.

Bažant, Z. P. (1984). "Size Effect in Blunt Fracture: Concrete, Rock, Metal." ASCE J. Eng. Mech., 110, 518-535.

Bažant, Z. P. (2000). "Size Effect." Int. J. Solids Struct., 37, 69-80.

Behloul, M. (1996). "Analyse et modélisation du comportement d'un matériau à matrice cimentaire fibrée à ultra hautes performances (Bétons de Poudres Réactives). Du matériau à la structure." PhD dissertation (in French), Ecole Normale Supérieure de Cachan.

Beremin, F. M. (1983). "A Local Criterion for Cleavage Fracture of a Nuclear Pressure Vessel Steel." Metallurgical Transactions A, 14A, 2277-2287.

Bluhm, J. I. (1969). "Fracture Arrest." In: Fracture, Academic Press, New York (USA), 1-63. 
Boulay, C., Le Maou, F., Renwez, S., Sercombe, J., and Toutlemonde, F. (1997). "Caractérisation du comportement au choc d'un béton de poudres réactives grâce à des essais de traction directe." LCPC report.

Broek, D. (1982). Elementary Engineering Fracture Mechanics. Martinus Nijhoff, The Hague, Netherlands.

Buzaud, E. (1998). "Performances mécaniques et balistiques du microbéton MB50." Report, DGA/Centre d'Etudes de Gramat.

Buzaud, E. (2003). "Unpublished work." DGA/Centre d'Etudes de Gramat.

Camacho, G. T., and Ortiz, M. (1996). "Computational Modelling of Impact Damage in Brittle Materials." Int. J. Solids Struct., 33 (20-22), 2899-2938.

da Silva, A. R. C., Proença, S. P. B., Billardon, R., and Hild, F. (2004). "Probabilistic Approach to Predict Cracking in Lightly Reinforced Microconcrete Pannels." J. Eng. Mech., 130 (8), 931-941.

Davies, D. G. S. (1973). "The Statistical Approach to Engineering Design in Ceramics." Proc. Brit. Ceram. Soc., 22, 429-452.

Denoual, C., Barbier, G., and Hild, F. (1997). "A Probabilistic Approach for Fragmentation of Ceramics under Impact Loading." C. R. Acad. Sci. Paris, 325 (Série IIb), 685-691.

Denoual, C., Cottenot, C. E., and Hild, F. (1996). "On the Identification of Damage during Impact of a Ceramic by a Hard Projectile." Proceedings 16th International Conference on BALLISTICS, APDS, Arlington (USA), 541-550.

Denoual, C., Cottenot, C. E., and Hild, F. (1998). "Analysis of the Degradation Mechanisms in an Impacted Ceramic." Proceedings Shock Compression of Condensed Matter, AIP Press, New York (USA), 427-430.

Denoual, C., and Hild, F. (1998). "On the Characteristic Scales involved in a Fragmentation Process." J. Phys., IV (8), 119-126. 
Denoual, C., and Hild, F. (2000). "A Damage Model for the Dynamic Fragmentation of Brittle Solids." Comp. Meth. Appl. Mech. Eng., 183, 247-258.

Denoual, C., and Hild, F. (2002). "Dynamic Fragmentation of Brittle Solids: A Multi-Scale Model." Eur. J. Mech. A/Solids, 21 (1), 105-120.

Drucker, D. C., and Prager, W. (1956). "Soil Mechanics and Plastic Analysis of Limit Design." Quat. of Appl. Math., 14,

Espinosa, H. D., Zavattieri, P. D., and Dwivedi, S. K. (1998). "A Finite Deformation Continuum/Discrete Model for the Description of Fragmentation and Damage in Brittle Materials." J. Mech. Phys. Solids, 46, 1909-1942.

Forquin, P. (2003). "Endommagement et fissuration de matériaux fragiles sous impact balistique, rôle de la microstructure." PhD dissertation (in French), Ecole Normale Supérieure de Cachan.

Forquin, P., Tran, L., Louvigné, P.-F., Rota, L., and Hild, F. (2003). "Effect of Aluminum Reinforcement on the Dynamic Fragmentation of SiC Ceramics." Int. J. Impact Eng., 28, 1061-1076.

Freund, L. B. (1972). "Crack Propagation in an Elastic Solid Subjected to General Loading Constant Rate of Extension." J. Mech. Phys. Solids, 20, 129-140.

Freund, L. B. (1990). Dynamic Fracture Mechanics. Cambridge University Press, Cambridge (UK).

Grady, D. E., and Kipp, M. E. (1980). "Continuum Modeling of Explosive Fracture in Oil Shale." Int. J. Rock Min. Sci. \& Geomech. Abstr., 17, 147-157.

Gulino, R., and Phoenix, S. L. (1991). "Weibull Strength Statistics for Graphite Fibres Measured from the Break Progression in a Model Graphite/Glass/Epoxy Microcomposite." J. Mater. Sci., 26 (11), 3107-3118. 
Hibbitt, H. D., Karlsson, B. I., and Sorensen, P. (2001). "Abaqus User's manual, ABAQUS/EXPLICIT 6.1." version 5.8, Volume I et II.

Hild, F., Forquin, P., and Silva, A. R. C. (2003). "Single and Multiple Fragmentation of Brittle Geomaterials." Rev. Franç. Gén. Civil, 7 (7-8), 973-1003.

Hornemann, U., Kalthoff, J. F., Rothenhäusler, H., Senf, H., and Winkler, S. (1984). "Experimental Investigation of Wave and Fracture Propagation in Glass - Slabs Loaded by Steel Cylinders at High Impact Velocities." EMI report E 4/84, Weil am Rhein (Germany).

Ibrahimbegovic, A., and Delaplace, A. (2003). "Microscale and mesoscale discrete models for dynamic fracture of structures built of brittle material." Comput. Struct., 81 (12), 12551266.

Jayatilaka, A. de S. (1979). Fracture of Engineering Brittle Materials. Applied Sciences Publishers, London (UK).

Jeulin, D. (1991). "Modèles morphologiques de structures aléatoires et changement d'échelle." thèse d'État, Université de Caen.

Kanninen, M. F., and Popelar, C. H. (1985). Advanced Fracture Mechanics. Oxford University Press, Oxford (UK).

Knauss, W. G., and Ravi-Chandar, K. (1985). "Some basic problems in stress wave dominated fracture."" Int. J. Fract., 27 (3-4), 127-143.

Knauss, W. G., and Ravi-Chandar, K. (1986). "Fundamental considerations in dynamic fracture." Eng. Fract. Mech., 23 (1), 9-20.

Kolsky, H. (1963). Stress Waves in Solids. Dover Publications, New York (USA).

Krieg, R. D. (1978). "A simple constitutive description for soils and crushable foams." report, SC-DR-7260883, Sandia National Laboratory.

Kurkjian, C. R. (1985). Strength of Inorganic Glass. Plenum Press, New York (USA). 
Malier, Y. (1992). Les bétons à hautes performances. Presses de l'ENPC.

Margolin, L. G. (1983). "Elasticity Moduli of a Cracked Body." Int. J. Fract., 22, 65-79.

Mastilovic, S., and Krajcinovic, D. (1999). "High-Velocity Expansion of a Cavity within a Brittle Material." J. Mech. Phys. Solids, 47, 577-600.

Pamshock (2001). "User's Manual." ESI.

Rajendran, A. M. (1994). "Modeling the Impact Behavior of AD85 Ceramic under Multiaxial Loading." Int. J. Impact Eng., 15 (6), 749-768.

Ravi-Chandar, K., and Knauss, W. G. (1982). "Dynamic crack-tip stresses under stress wave loading. A comparison of theory and experiment." Int. J. Fract., 20 (3), 209-222.

Ravi-Chandar, K., and Knauss, W. G. (1984a). "An experimental investigation into dynamic fracture: I, Crack initiation and arrest." Int. J. Fract., 25 (4), 247-262.

Ravi-Chandar, K., and Knauss, W. G. (1984b). "An experimental investigation into dynamic fracture: II, Microstructural aspects." Int. J. Fract., 26 (1), 65-80.

Ravi-Chandar, K., and Knauss, W. G. (1984c). "An experimental investigation into dynamic fracture: III, Steady-state crack propagation and crack branching." Int. J. Fract., 26 (2), $141-154$.

Ravi-Chandar, K., and Knauss, W. G. (1984d). "An experimental investigation into dynamic fracture: IV, On the interaction of stress waves with propagating cracks." Int. J. Fract., $26(3), 189-200$.

Richard, P., and Cheyrezy, M. (1995). "Composition of reactive power concretes." Cement Conc. Res., 25 (7), 1501-1511.

Riou, P., Denoual, C., and Cottenot, C. E. (1998). "Visualization of the Damage Evolution in Impacted Silicon Carbide Ceramics." Int. J. Impact Eng., 21 (4), 225-235. 
Schwer, L. E., Rosinsky, R., and Day, J. (1988). "An axisymmetric lagrangian technique for predicting earth penetration including penetrator response." Int. J. Num. Anal. Meth. Geomech., 12, 235-262.

Sharon, E., Gross, S. P., and Fineberg, J. (1995). "Local crack branching as a mechanism for instability in dynamic fracture." Phys. Rev. Lett., 74 (25), 5096-5099.

Shockey, D. A., Curran, D. R., Seaman, L., Rosenberg, J. T., and Petersen, C. F. (1974). "Fragmentation of Rocks under Dynamic Loads." Int. J. Rock Mech. Min. Sci., 11, 303317.

Sieradzki, K., and Dienes, G. J. (1988). "Atomistics of crack propagation." Acta Metall., 36 (3), 651-663.

Strassburger, E., and Senf, H. (1994). "Experimental Investigations of Wave and Fracture Phenomena in Impacted Ceramics." EMI report 3/94.

Strassburger, E., and Senf, H. (1995). "Experimental Investigations of Wave and Fracture Phenomena in Impacted Ceramics and Glasses." Report, ARL-CR-214, ARL.

Strassburger, E., Senf, H., and Rothenhäusler, H. (1994). "Fracture Propagation during Impact in Three Types of Ceramics." J. Physique IV, coll. C8 (suppl. IV), 653-658.

Swenson, D. V., and Taylor, L. M. (1983). "A finite element model for the analysis of tailored pulse stimulation of boreholes." Int. J. Num. Analyt. Meth. Geomech., 7, 469-484.

Weibull, W. (1939). "A Statistical Theory of the Strength of Materials." Report 151, Roy. Swed. Inst. Eng. Res.

Weibull, W. (1951). "A Statistical Distribution Function of Wide Applicability." ASME J. Appl. Mech., 18 (3), 293-297.

Zhou, S. J., Lomdahl, P. S., Thomson, R., and Holian, B. L. (1996). "Dynamic Crack Processes via Molecular Dynamics." Phys. Rev. Lett., 76 (13), 2318-2321. 


\section{Table captions}

Table 1 - Weibull and elastic parameters of unreinforced and fiber reinforced Ductal ${ }^{\circledR}$.

Table 2 - Parameters of the fragmentation model coupled with the KST model for unreinforced and fiber reinforced Ductal $^{\circledR}$. 
Table 1 - Forquin and Hild

\begin{tabular}{|c|c|c|}
\hline Material & $\begin{array}{c}\text { Unreinforced } \\
\text { Ductal }^{\circledR}\end{array}$ & $\begin{array}{c}\text { Fiber reinforced } \\
\text { Ductal }^{\circledR}\end{array}$ \\
\hline Young's Modulus (GPa) & 57.2 & 58.1 \\
\hline Poisson's ratio $v$ & 0.18 & 0.18 \\
\hline Density & 2.39 & 2.49 \\
\hline Volume fraction of fibers (\%) & - & 2 \\
\hline Mean crack initiation stress $\sigma_{w}(\mathrm{MPa})$ & 22 & 17 \\
\hline Weibull modulus (crack initiation) $m$ & 11 & 14 \\
\hline Effective volume (crack initiation) $V_{\text {eff }}\left(\mathrm{mm}^{3}\right)$ & 53 & 30 \\
\hline Mean ultimate strength $\sigma_{\max }(\mathrm{MPa})$ & 22 & 25 \\
\hline Number of tested samples (3-point flexure) & 18 & 9 \\
\hline
\end{tabular}


Table 2 - Forquin and Hild

\begin{tabular}{|c|c|c|}
\hline Density, Elastic parameters & $\rho ; E ; \nu$ & 2.390; $57 \mathrm{GPa} ; 0.18$ \\
\hline \multicolumn{3}{|c|}{ Parameters of the spherical behavior } \\
\hline Initial et final bulk moduli & $K_{i} ; K_{f}$ & 24.1 GPa; 34.0 GPa, \\
\hline \multirow[t]{4}{*}{ Compaction curve (4 points) } & $\varepsilon_{v}^{(i)} ; P^{(i)}$ & $0 ; 0$ \\
\hline & & $-0.013 ; 320 \mathrm{MPa}$ \\
\hline & & $-0.04 ; 600 \mathrm{MPa}$ \\
\hline & & $-0.059 ; 900 \mathrm{MPa}$ \\
\hline \multicolumn{3}{|c|}{ Parameters of the deviatoric behavior } \\
\hline Coefficient of elliptic equation & $a_{0} ; a_{1} ; a_{2}$ & $10^{4} \mathrm{MPa}^{2} ; 515 \mathrm{MPa} ; 0.384$ \\
\hline Maximum and minimum stresses & $\sigma_{e q}^{\max } ; \sigma_{e q}^{\min }$ & 750 MPa; $222 \mathrm{MPa}$ \\
\hline \multicolumn{3}{|c|}{ Parameter of the fragmentation model } \\
\hline Cracks initiation (Weibull) parameters & $\sigma_{w} ; m ; V_{e f f}$ & $22 \mathrm{MPa} ; 11 ; 53 \mathrm{~mm}^{3}$ \\
\hline Cracks propagation parameters & $k ; C_{0}$ & $0.38 ; 4880 \mathrm{~m} / \mathrm{s}$ \\
\hline
\end{tabular}




\section{Figure captions}

Figure 1: $\quad$ Composition and size of components in Ductal ${ }^{\circledR}$.

Figure 2: $\quad$ Stress / displacement curves for unreinforced and fiber reinforced Ductal ${ }^{\circledR}$. For reinforced Ductal ${ }^{\circledR}$, the exterme realizations are shown. For unreinforced Ductal $^{\circledR}$, an elastic-brittle response is always obtained.

Figure 3: Fracture pattern in 3-point flexure for unreinforced (a) and fiber reinforced (b) Ductal $^{\circledR}$.

Figure 4: Schematic of the sarcophagus configuration with dynamic confinement and

Figure 5: Edge-on impact modeling with an elastoplastic model $\left(\sigma_{\mathrm{y}}=400 \mathrm{MPa}\right)$ : (a) mesh of a quarter, von Mises contours $30 \mu$ s after impact with an aluminum projectile, impact velocity $=80 \mathrm{~m} / \mathrm{s}$ (b), and steel projectile, impact velocity $=130 \mathrm{~m} / \mathrm{s}$ (c), (d) pressure contours (aluminum projectile, impact velocity $=80 \mathrm{~m} / \mathrm{s}$ ) $8 \mu \mathrm{s}$ after impact.

Figure 6: Experimental configuration of EOI experiments.

Figure 7: Visualization of damage change during edge-on-impact of a steel projectile (ultrahigh speed camera configuration, impact velocity $=130 \mathrm{~m} / \mathrm{s}$ ): (a) unreinforced Ductal $^{\circledR}$, (b) fiber reinforced Ductal ${ }^{\circledR}$.

Figure 8: Damage pattern after edge-on-impact (sarcophagus configuration): (a) aluminum projectile (impact velocity $=88 \mathrm{~m} / \mathrm{s}$ ), (b) steel projectile (impact velocity $=130 \mathrm{~m} / \mathrm{s})$. 
Figure 9: Compaction data used in the present model, pressure $P$ versus volumetric strain $\varepsilon_{\mathrm{v}}$ for fiber reinforced Ductal ${ }^{\circledR}$. In the model, the effect of the fibers on the response $\left(P, \varepsilon_{\mathrm{V}}\right)$ is neglected.

Figure 10: Crack density at saturation and ultimate tensile strength versus normalized crack velocity $\left(V_{\text {cracking }} / C_{0}=k\right)$ for a stress rate of $10 \mathrm{MPa} / \mu \mathrm{s}$.

Figure 11: Damage variable (left) and crack density (right) associated with the maximum principal stress direction $30 \mu$ s (a) and $45 \mu$ s (b) after impact by an aluminum projectile (impact velocity $=88 \mathrm{~m} / \mathrm{s}$ ).

Figure 12: Damage variable (left) and cracking density (right) associated with the maximum principal stress direction $30 \mu \mathrm{s}$ (a) and $45 \mu$ s (b) after impact by a steel projectile (impact velocity $=130 \mathrm{~m} / \mathrm{s}$ ). 


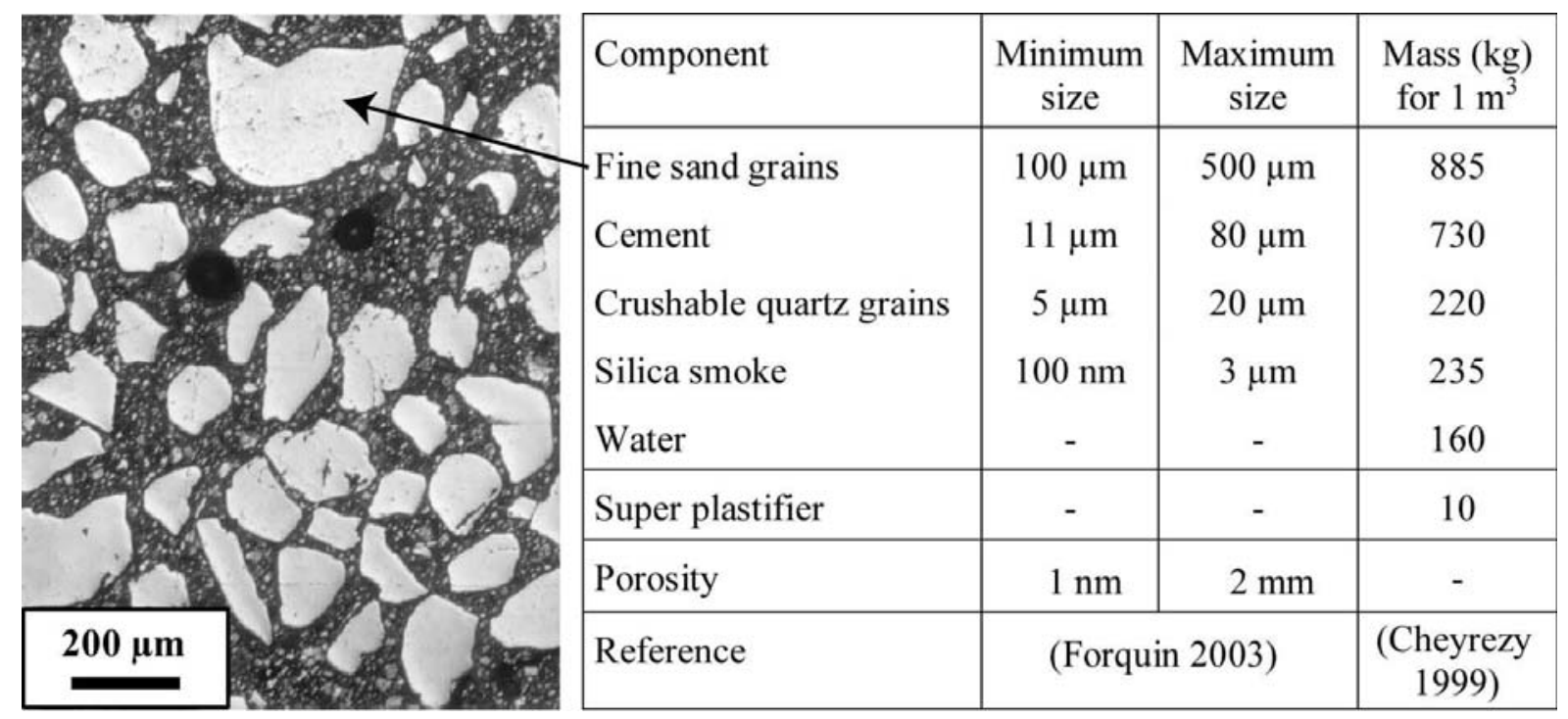

Figure 1 - Forquin and Hild 


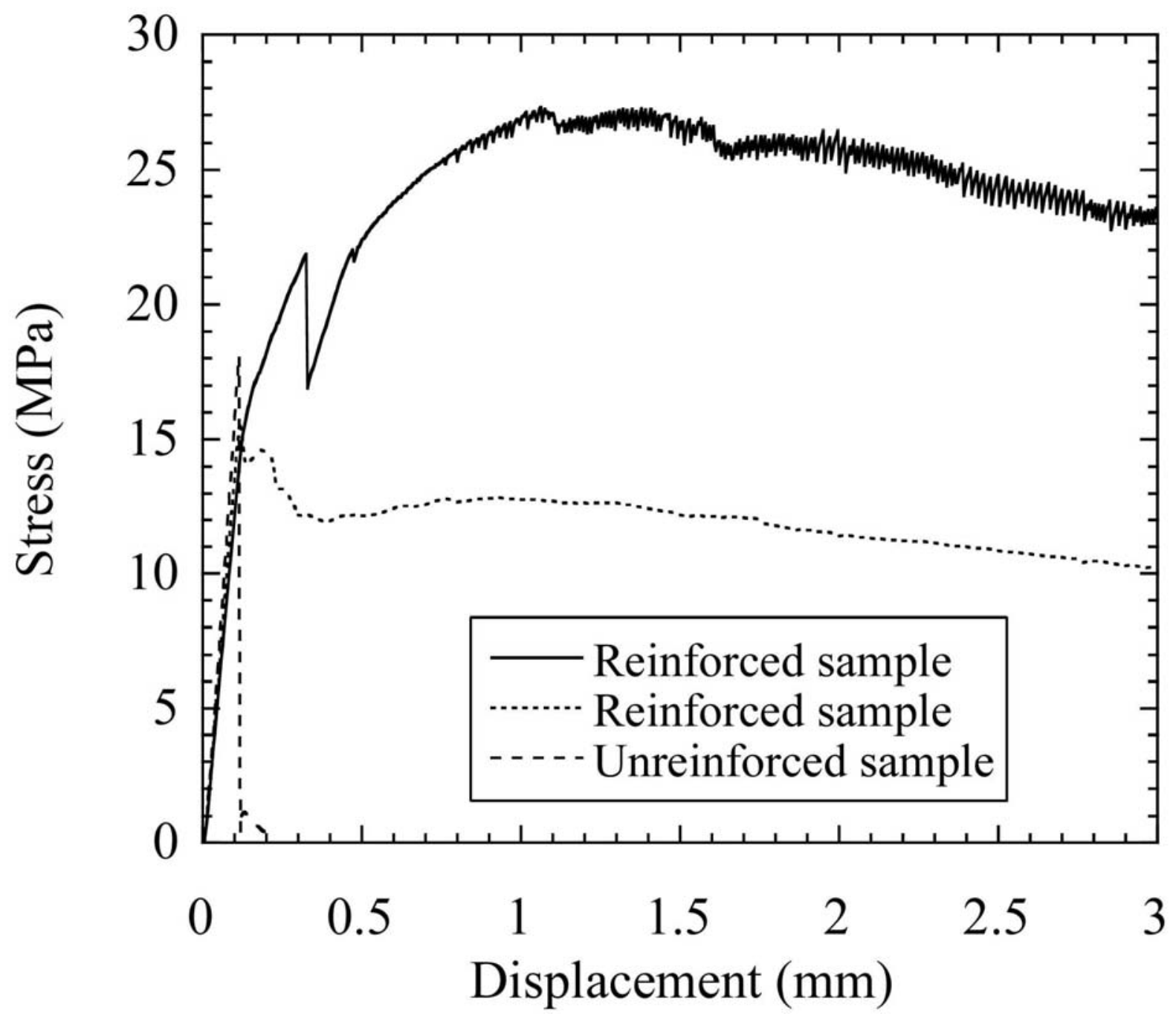

Figure 2 - Forquin and Hild 


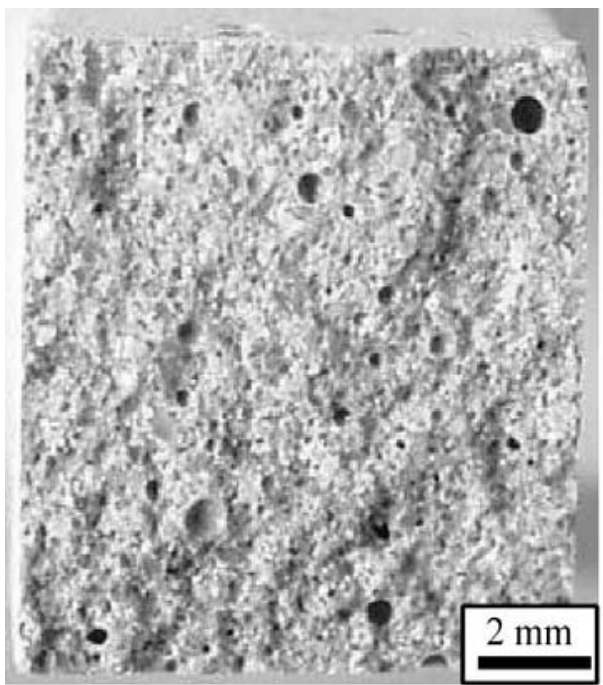

-a-
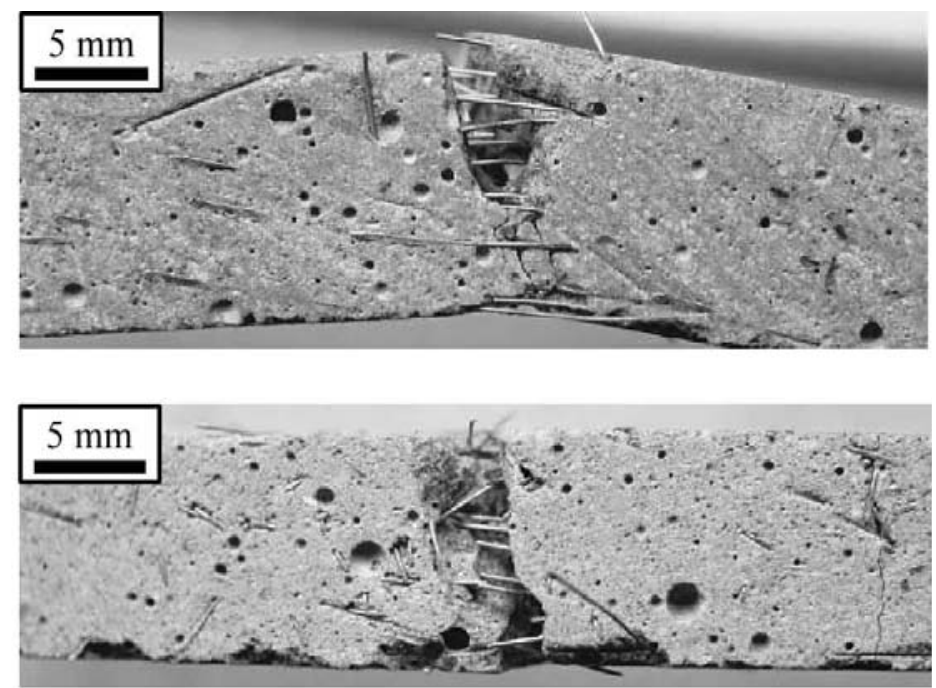

-b-

Figure 3 - Forquin and Hild 


\section{Aluminum \\ sarcophagus}
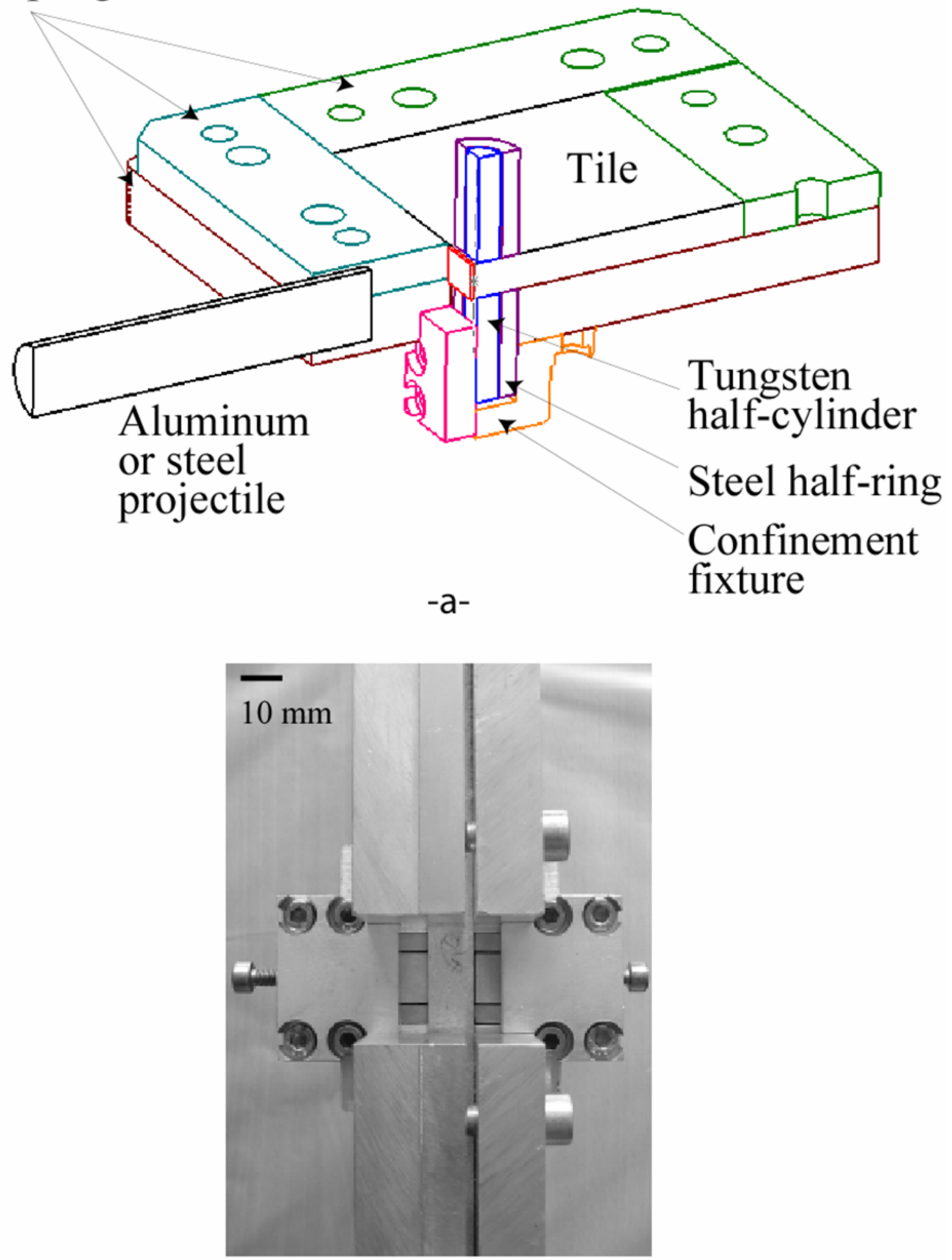

$-b-$

Figure 4 - Forquin and Hild 


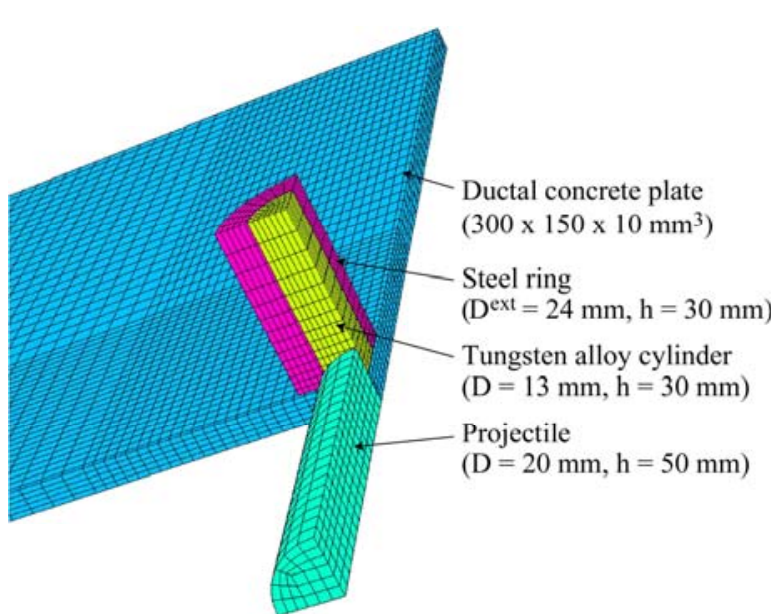

-a-

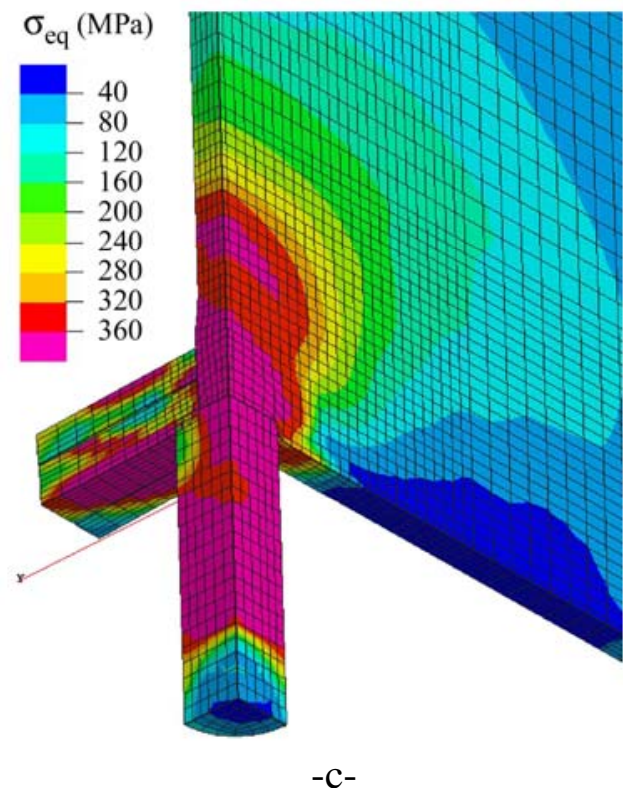

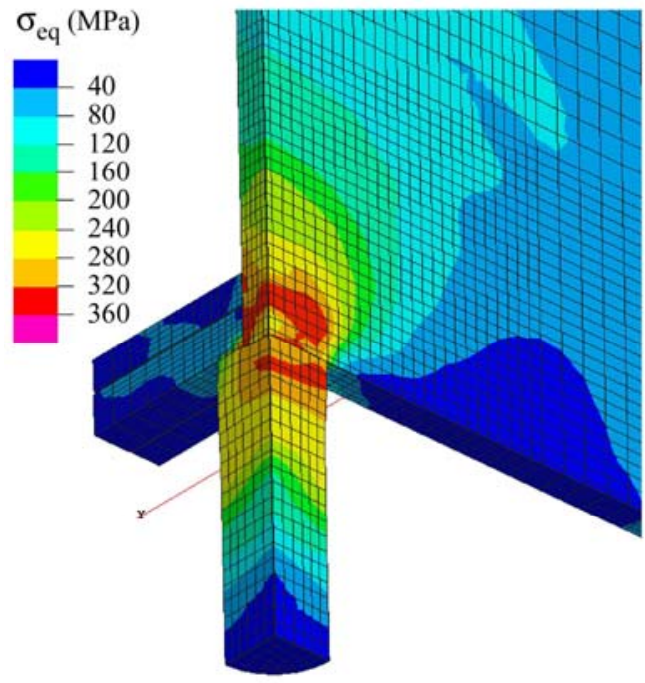

-b-

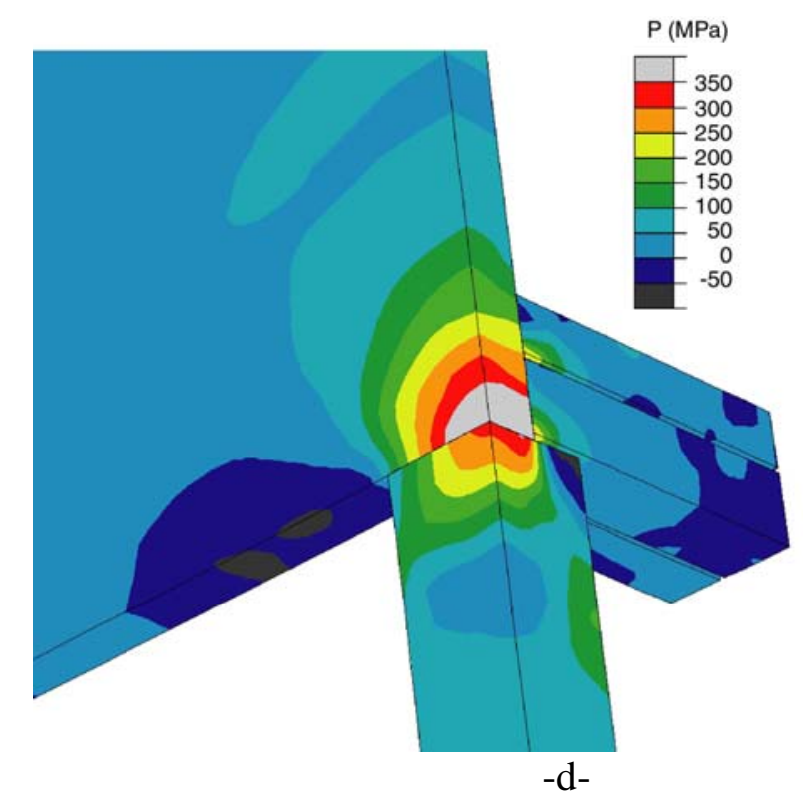

Figure 5 - Forquin and Hild 


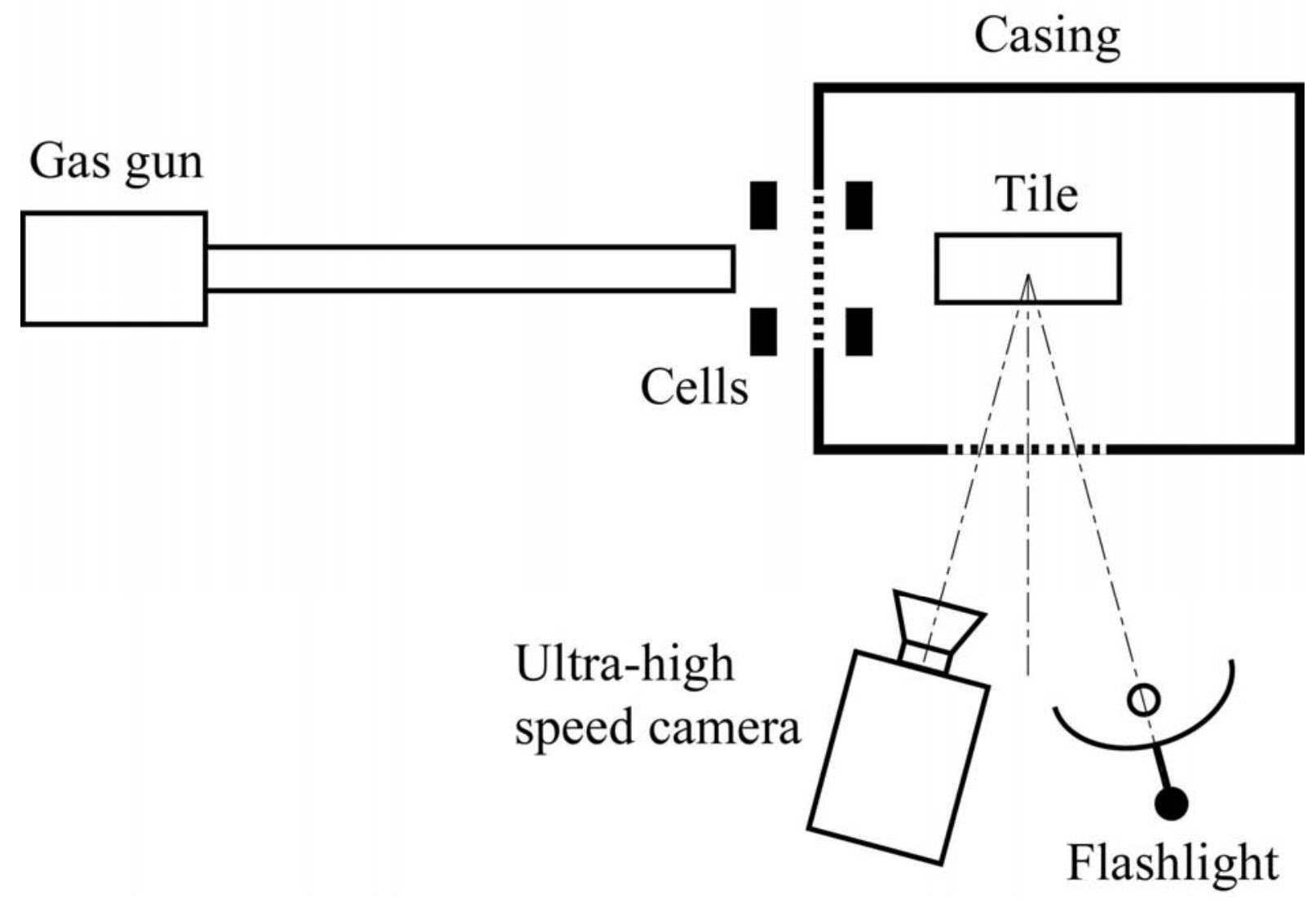

Figure 6 - Forquin and Hild 

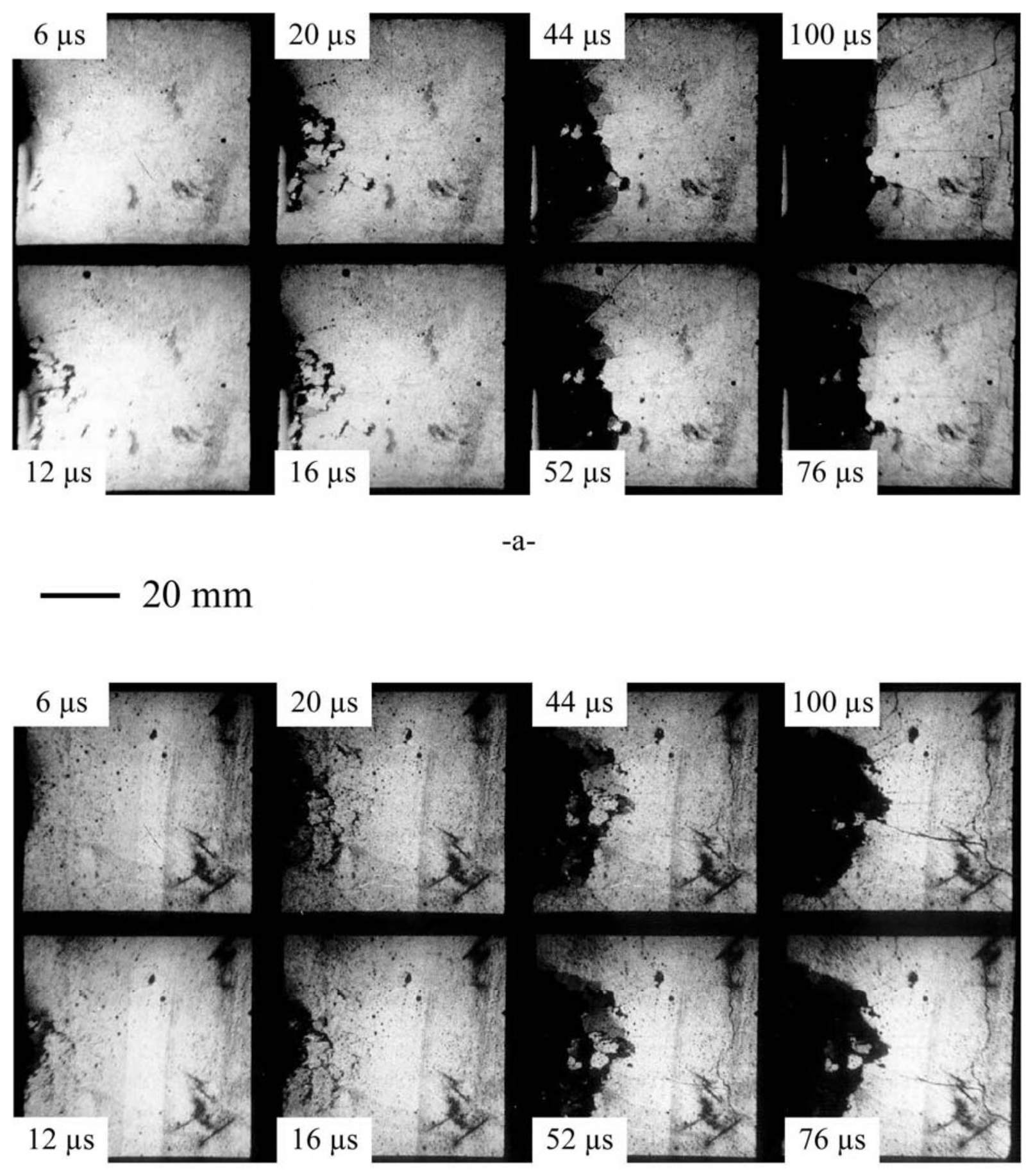

-b-

Figure 7 - Forquin and Hild 

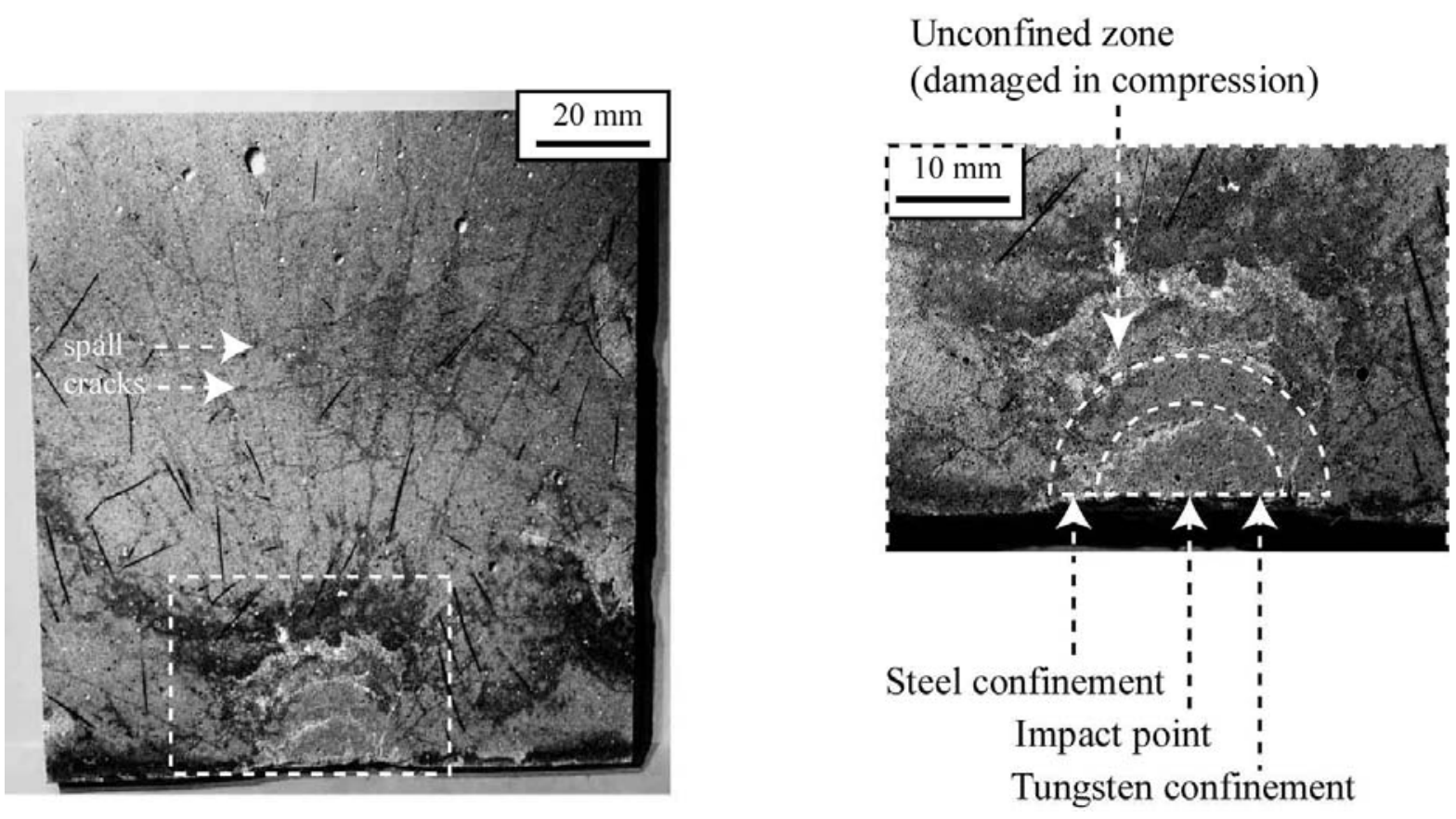

-a-

Cracks at $45^{\circ}$ wrt. radial and hoop directions

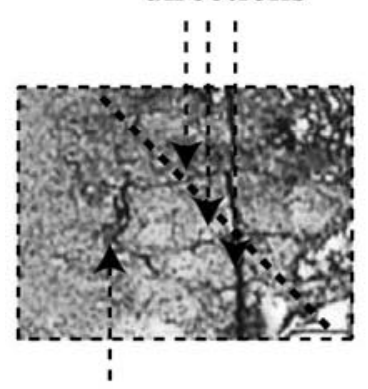

Emerging crack

Line of a gauge wire Damaged zone in compression

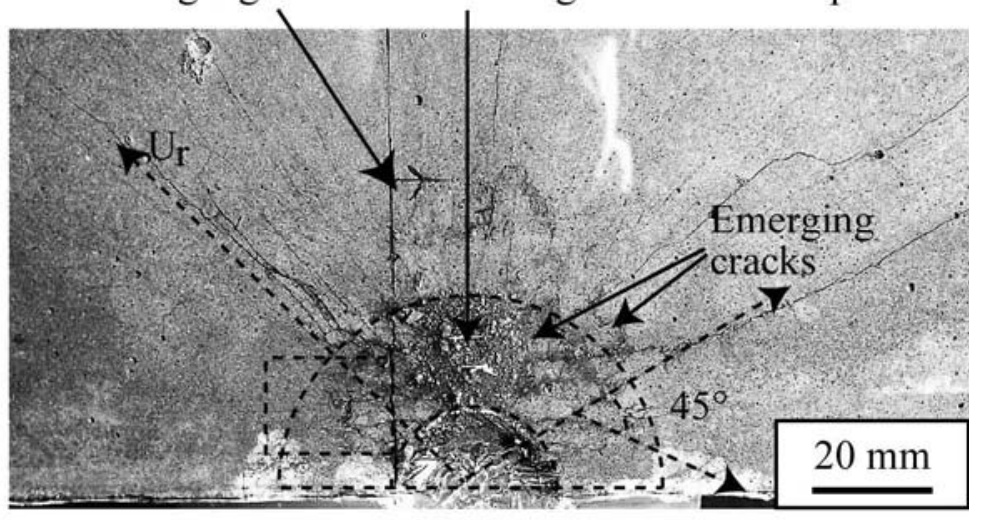

-b-

Figure 8 - Forquin and Hild 


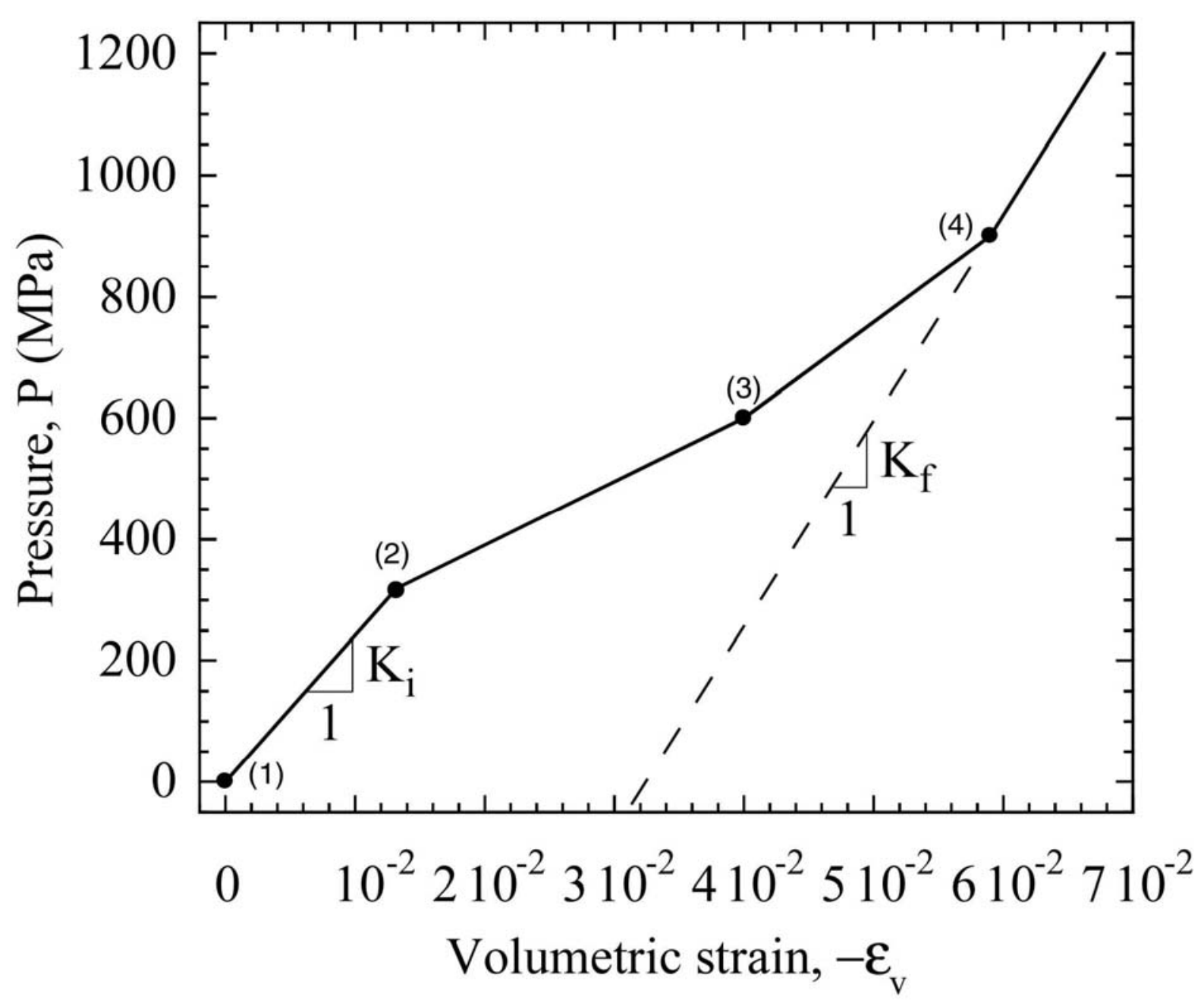

Figure 9 - Forquin and Hild 


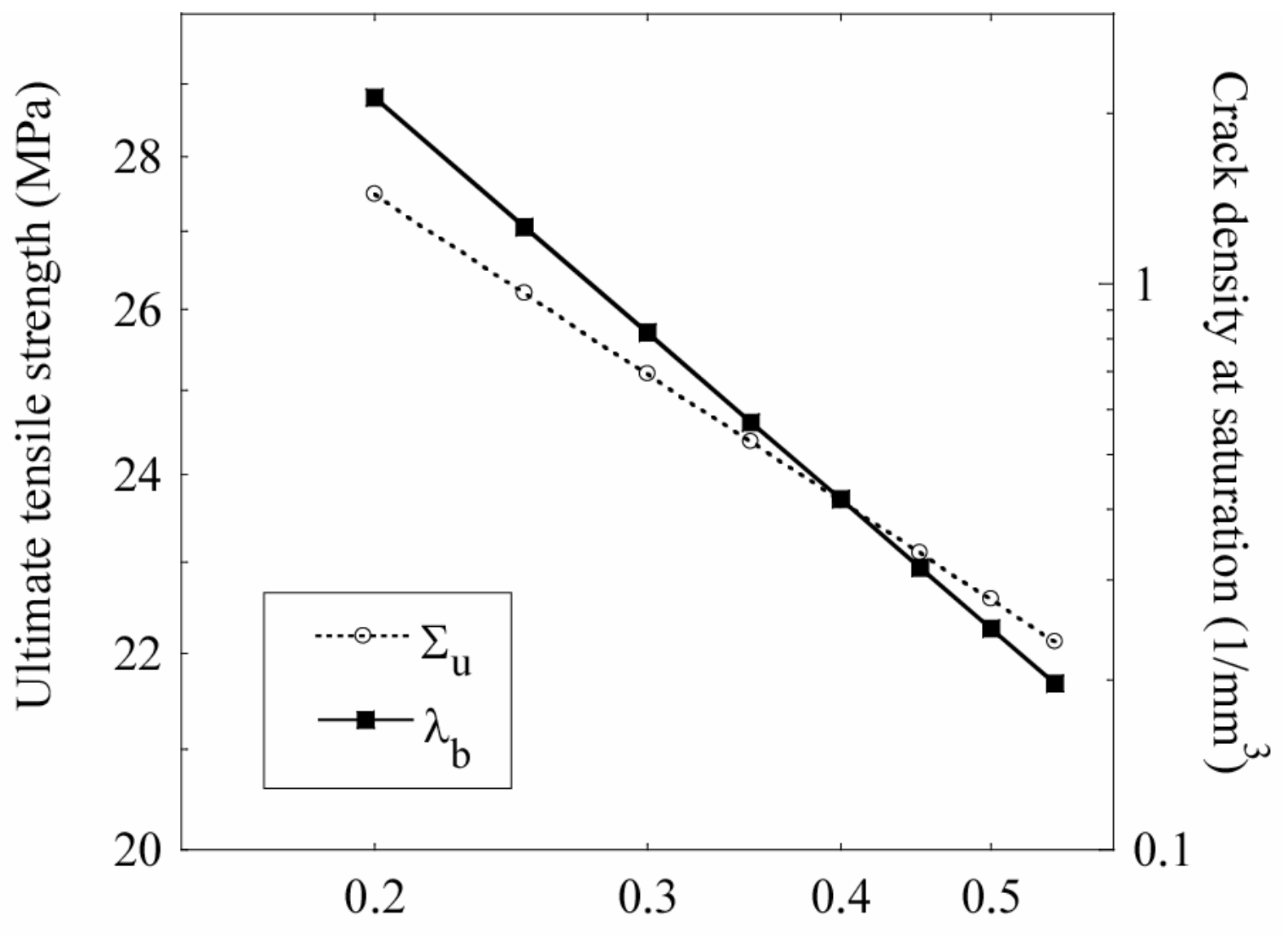

Crack propagation paramer, $\mathrm{k}$

Figure 10 - Forquin and Hild 


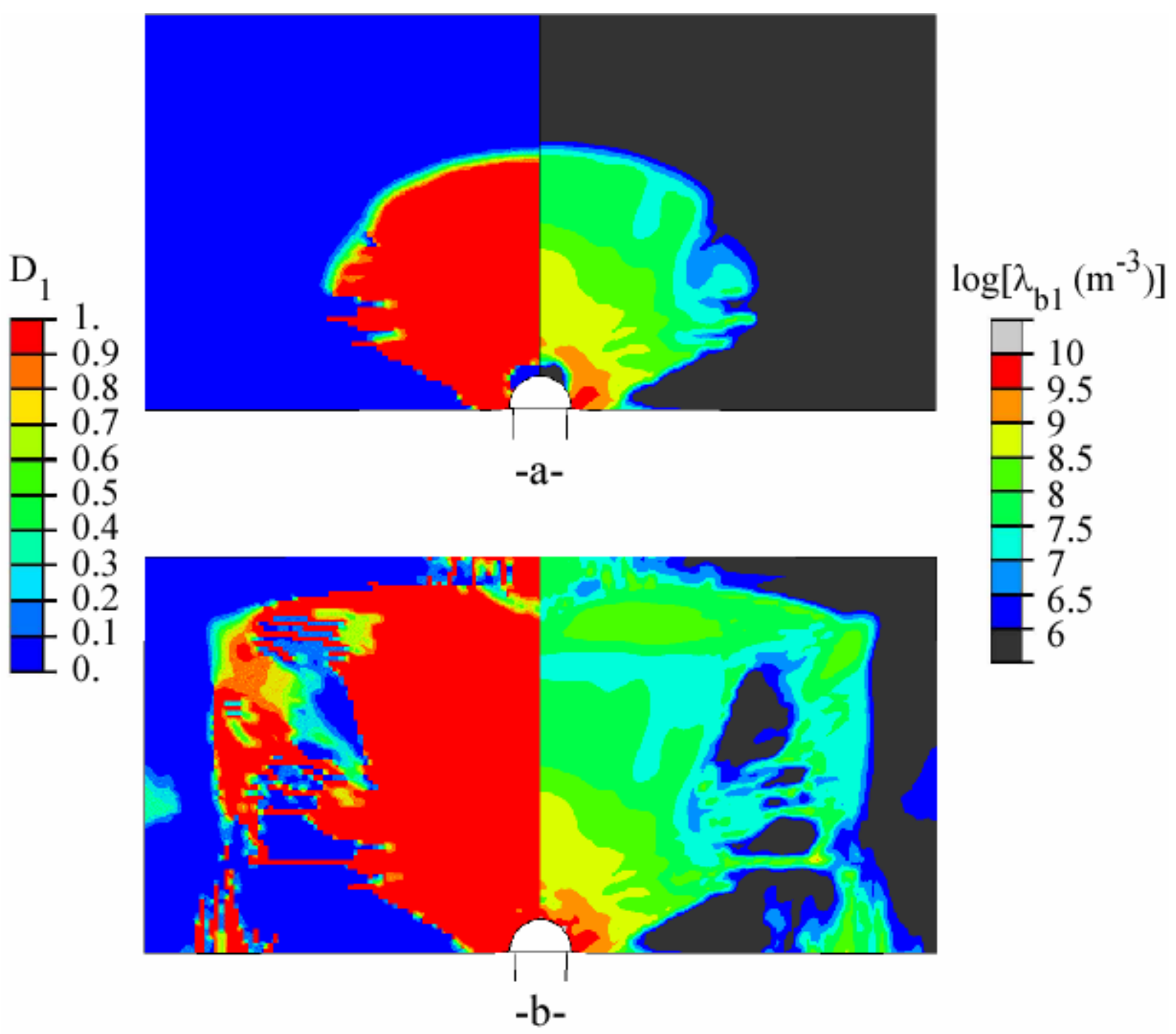

Figure 11 - Forquin and Hild 


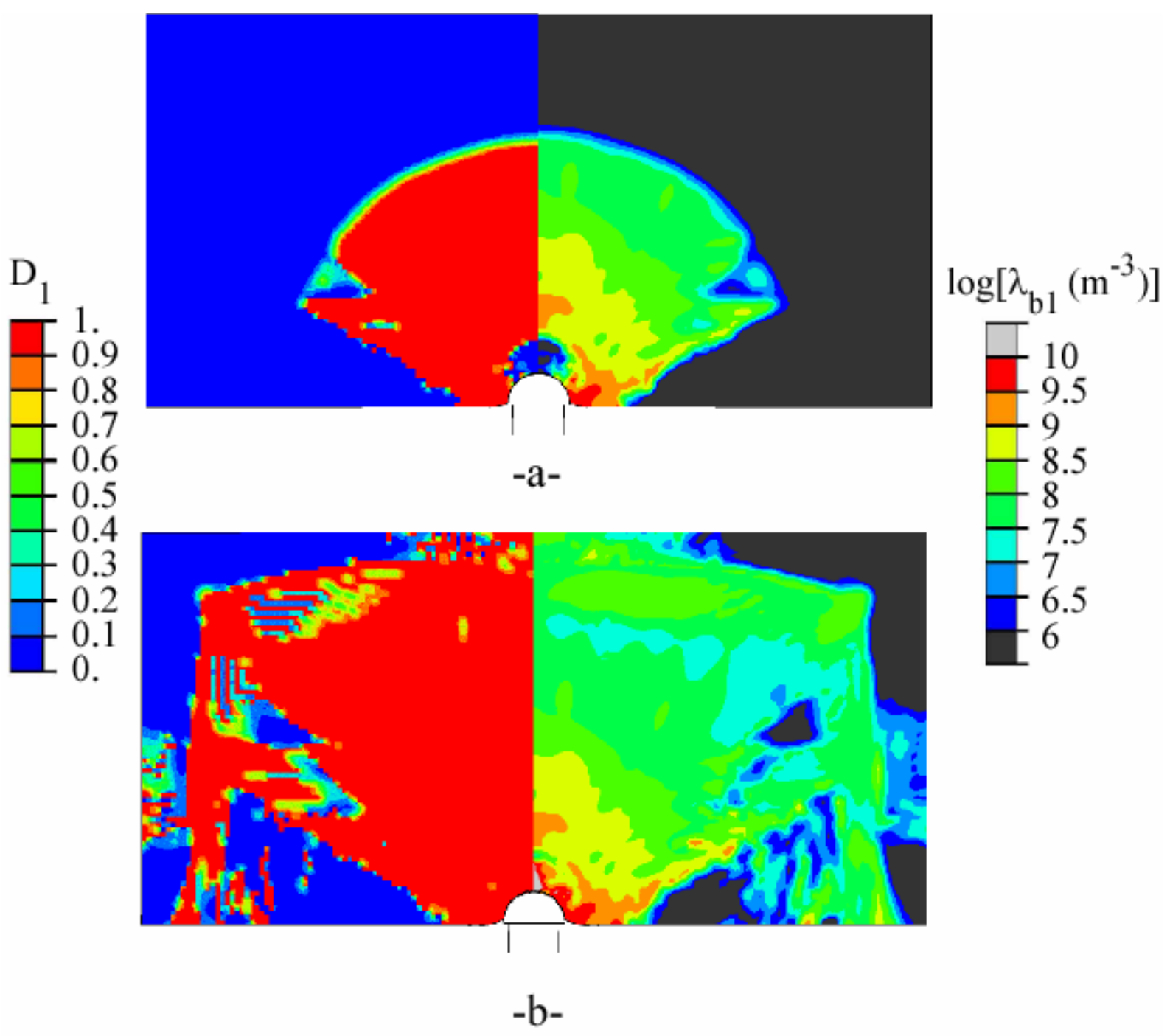

Figure 12 - Forquin and Hild 